Ministerstwo Nauki

i Szkolnictwa Wyższego

Digitalizacja archiwalnych numerów czasopisma naukowego Analecta Cracoviensia 1-24 (1969-1992)

i ich publikacja w otwartym dostępie - zadanie finansowane w ramach umowy 672/P-DUN/2017 ze środków

Ministra Nauki i Szkolnictwa Wyższego przeznaczonych na działalność upowszechniającą naukę

\title{
JEAN GAUDEMET
}

Université de Droit, d'Economie et de Sciences Sociales de Paris

Au Professeur Adam Vetulani dont les savants travaux ont inspiré quelques unes de ces pages.

\section{LES MODALITÉS DE RÉCEPTION DU DROIT A LA LUMIÉRE DE L'HISTOIRE COMPARATIVE *}

Que le droit apparaisse comme une technique qui s'efforce d'organiser la cohabitation humaine ou que, dans une vue moins pessimiste, on le tienne pour l'expression d'une société, de ses aspirations et de ses nécessités, de sa structure politique et de son agencement social, le „phénomène juridique" ne peut laisser l'historien indifférent. Expression d'une époque, le droit est lié au territoire qui l'a vu se former, que cette formation soit l'oeuvre lente et obscure de la coutume, le trait de génie d'un législateur inspiré... ou, plus modestement, le difficile compromis d'opinions divergentes.

Mais l'Histoire montre aussi que la règle de droit dépasse parfois les rivages qui l'ont vu naître, qu'elle rayonne au loin et s'impose dans des pays pour lesquels elle n'avait pas été faite.

Réception, pénétration, infiltration, influence, autant de termes employés les uns pour les autres et sans qu'on y attache grande importance pour signifier cette expansion. Certains se sont cependant efforcé de les distinguer.

Dans une Note sur les contacts entre les systèmes juridiques, H. Levy Bruhl distinguait „l'emprunt limité” de certaines institutions et „la sub-

* Il nous est agréable d'offrir en témoignane d'admiration et d'amitié ces réflexions à l'un des Maîtres de l'histoire du droit en Pologne. Son pays, à plusieurs reprises, connut ces phénomènes de réception et les historiens polonais - outre le jubilaire - sont nombreux à avoir contribué, pour des époques diverses, à une meilleure connaissance de ces rencontres de droits ( $\mathrm{K}$. Bukowska, H. Kupiszewski, Kutrzeba, J. Modrzejewski, R. Taubenschlag). 
stitution intégrale ou quasi intégrale”, le „changement de structure” que l'on pourrait qualifier de „Révolution" 1.

Etudiant La pénétration du droit savant dans les coutumiers angevins et bretons au Moyen-Age 2, J. P. Levy opposait la „réception” (,Eindringen") où il voit une acceptation quasiment officielle d'un droit étranger, à la „,pénétration”, souvent plus sporadique et moins massive ${ }^{3}$. Celle-ci lui paraissait pouvoir n'être que „superficielle” (emploi d'une terminologie; citation; passages traduits et simplement plaqués; adoption d'un plan d'exposition; toutes choses qui ne touchent pas le fond du droit); ou „substantielle”, et alors il s'agit d'emprunt de règles ou d'institutions.

C'est à propos de la „réception" du droit romain en Allemagne que ces questions de vocabulaire ont été le plus étudiées pour aboutir d'ailleurs souvent à des terminologies différentes. Alors que H. Mitteis réservait „réception" pour l'introduction du droit romain en Allemagne et parlait pour les autres pays „d'Aufnahme des Fremdrechts”, M. Coing distingue pour l'Allemagne une „Früh-Rezeption” (jusqu'au milieu du $\mathrm{XV}^{\mathrm{e}}$ ) et une ,eigentliche Rezeption" de la fin du XVe au XVIII ${ }^{\mathrm{e}}$ siécle, la différence ${ }^{4}$ tenant plus à l'ampleur qu'aux modes de cette réception.

R. Feenstra ${ }^{5}$ adopte ce vocabulaire et réserve le terme d',,infiltration" pour l'introduction d'élément de droit romain vulgaire avant le XII siècle.

On pourrairt, mais sans grand profit, donner d'autres exemples de ces imprécisions terminologiques. Plus importantes sont les causes de cette propagation. Sans beaucoup insister, Levy-Bruhl ${ }^{6}$ signalait la conquête et évoquait à ce propos les suites de la victoire militaire ou de la colonisation.

C'était dans la même voie que s'était engagé Koschaker ${ }^{7}$ lorsqu'il écrivait: „La réception d'un système juridique n'est pas une question de qualité... c'est bien plus une question de puissance (Machtfrage) la suite d'une position de force, au moins spirituelle et culturelle... que cette force soit actuelle ou qu'elle ait laissé un souvenir vivant".

Il donnait comme preuve de cette affirmation le prestige dont avait joui le BGB de sa publication à 1914, au temps de l'apogée de I'Empire allemand. La défaite de 1919 autant que le déclin de la science pan-

1 Symbolae Taubenschlag, I = Eos, XLVIII (1956) 29.

2 Tijdschrift voor Rechtgeschiedenis, XXV (1957) 1-53.

3 p. 2.

4 On y reviendra plus loin.

5 Zur Rezeption in den Niederlanden, Studi in memoria di P. Koschaker, I, Milano $1954,250$.

6 Op. cit.

7 Europa und das römische Recht, 138. 
dectiste allemande auraient marqué la fin de cette hégémonie. La Turquie en 1926 se tournait vers le Code suisse.

A quoi un juriste turc rétorquait ${ }^{8}$ que cette adoption du droit civil et du droit des obligations suisse fut justifiée en Turquie en 1926 par la qualité du „,code le plus moderne, le plus complet et le plus démocratique".

Mais lorsque Koschaker parlait d',une position de force au moins spirituelle et culturelle", il évoquait d'autres facteurs que la contrainte politique ou la conquéte militaire. A côté de la force, il alléguait l'esprit. Réduite à ces deux termes, la dialectique devient simpliste. Nous voudrions ici par l'examen de quelques exemples historiques précis tenter de mieux cerner les formes et les causes de ces contacts juridiques.

Dans l'immense champ d'investigation qu'offre l'Histoire, nous retiendrons trois cas, tous occidentaux, mais qui nous mettent en présence de sociétés et donc de conditions bien diverses: ceux de la Rome classique, de l'Occident médiéval, de l'Europe du XIX ${ }^{\mathrm{e}}$ siècle ${ }^{9}$.

\section{I - LA ROME CLASSIQUE}

Fusion politique et unification juridique

Plus encore que par l'immensité de sa conquête, Rome nous frappe par l'attitude qu'elle sut adopter ż l'égard des vaincus. Sans doute le vae victis est-il romain et la conquête fut exploitation, pillage, ,imperialisme" ${ }^{10}$. Mais, comme tous les conquérants antiques, Rome n'imposa par la contrainte ni sa langue, ni son droit, ni sa religion. Tirant profit des provinces, elle laisse les provinciaux vivre selon leurs usages ${ }^{11}$, crée des villes (colonies ou municipes) de type romain et où s'organise une vie administrative ${ }^{12}$ et sociale ${ }^{13}$ à la romaine. Ce sont les provinciaux, au moins dans leur bourgeoisie citadine, qui viennent à Rome et

8 Ayiter F., Das Rezeptionsproblem im Zeichen der Kulturhistorischen Perspektive ,Europa und das röm. Recht” und unter besonderer Berücksichtigung der Rezeption Westeuropäischer Gesetzbücher in der modernen Turkei, Studi in memoria di P. Koschaker, II, Milano 1954, 133-156.

${ }_{9}$ D'autres champs d'étude ne seraient pas moins riches: ceux du monde musulman, des deux Amériques aux XVI et XVIIe siècles, des terres colonisées au XIXe et au début du XXe siècle. La pénétration du droit romain dans la première législation des monarchies barbares a été étudiée à propos du code d'Euric (vers 473) par E. Levy, The reception of highly developed legal system by peoples of different culture, Washington Law Review, XXV (1950) $236-242=$ Gesammelte Schriften, I (1963) 212-217.

${ }_{10} \mathrm{~L}$. Homo, L'Italie primitive et les débuts de l'impérialisme romain, $\mathrm{Pa}-$ ris 1925 .

${ }_{11}$ Cicéron en témoigne: les Grecs de Cilicie peuvent inter se disceptare suis legibus (ad Att. 6, 1, 15) cf. G. Puglies e, Editto di Cicerone in Cilicia, Syntelia Arangio-Ruiz, Napoli 1964, I, 974.

${ }_{12}$ Curies, assemblées, magistrats.

13 Les monuments essentiels en témoignent: Forum, Capitole, Thermes, théatres et amphithéatres, portiques et bibliothèques. 
„se romanisent”. Leur fidélité à Rome, leur confiance en son éternité ne se laisseront pas arrêter par les désastres et les Invasions. Et les derniers à dire sa grandeur seront des provinciaux; gaulois comme Rutilius Namatianus, ou africain comme Augustin.

Rome de son côté, orgueilleuse de sa gloire, sûre de sa supériorité, s'est montrée sous l'Empire accueillante. La qualité juridique de citoyen, privilège envié et fierté de ses titulaires, est de plus en plus généreusement accordée aux vaincus de la veille. Après sa concession aux Italiens au I ${ }^{\text {er }}$ siècle avant notre ère, ce sont au cours des deux premiers siècles de l'Empire des concessions de plus en plus larges aux provinciaux, selon des procédures que l'on n'a pas à rappeler ici. Et le mouvement s'achève lorsqu'en 212 Caracalla donne ,à tous les pérégrins qui sont sur terre la citoyenneté romaine" ${ }^{14}$.

Or l'un des privilèges du citoyen était d'avoir accès aux actes du ius civile (droit des citoyens). Donner la citoyenneté aux provinciaux c'était leur ouvrir non seulement cette partie du droit romain qualifié de ius gentium, qui était accessible aussi bien aux non romains qu'aux citoyens, mais aussi le ius civile; c'était leur ouvrir le plein accès au droit romain.

1. Ainsi s'instaurait un premier type de rencontre de droit. Les provinciaux en effet avaient, comme on l'a dit, conservé leurs usages malgré la conquête romaine et, en leur conférant la qualité de citoyen, Rome ne les privait pas de leur droit propre. Mais par cette qualité nouvelle, ils acquéraient la possibilité d'user aussi du droit romain. „Double citoyenneté" dit-on volontiers ${ }^{15}$ et possibilité d'option pour l'usage local ou le droit romain. Cette option n'était d'ailleurs pas globale et faite une fois pour toute, comme l'est aujourd'hui une option de nationalité. C'est en chaque affaire et dans la mesure où il le voulait que le nouveau citoyen choisissait entre son droit propre et le droit romain.

Solution toute de souplesse qui n'imposait pas le droit romain. Comment fut-elle appliquée? On ne le sait que fort imparfaitement. Car on ne pourrait étudier cette application qu'à travers l'examen d'actes juridiques innombrables et de multiples décisions judiciaires. Ces dernières font quasi-totalement défaut ${ }^{16}$. Quant aux actes de la pratique on n'en a un grand nombre que dans les papyrus d'Egypte. Et ceux-ci n. 88 .

14 Pap. de Giessen 40 col. I dans Fontes iuris romani anteiustiniani, I, Leges

15 La notion est contestée. Admise par F. de Visscher et Schönbauer, elle est repoussée par Arangio-Ruiz, Luzzatto ou de Martino.

16 L'attitude des administrateurs est étudiée par $\mathrm{H}$. A n k u m, Die Haltung der Präfekten von Aegypten gegenüber den greco-ägyptischen Recht, RIDA XVIII (1971) 367-399. 
ont été étudiés avec soin, dans la mesure encore très incomplète, où ils sont édités ${ }^{17}$. De cette étude minutieuse, souvent fort difficile, se dégagent les constations suivantes:

a) Par traditionnalisme et aussi par ignorance du droit romain, les praticiens locaux continuèrent souvent à se référer aux usages locaux après $212^{18}$. Peut-être d'ailleurs cette fidélité à la tradition fut-elle soutenue par des considérations affectives. L'organisation familiale, le mode de dévolution des biens à la suite du décès de leur titulaire ne sauraient facilement être boulversés par un droit nouveau. La liberté du choix servait ici le maintien des coutumes ancestrales ${ }^{19}$. L'usage de la langue ne doit pas non plus être négligé. Si les parties ou plus encore le scribe ignoraient le latin, il leur était bien difficile d'user du droit romain.

b) Mais si le conservatisme des scribes, les considérations familiales. la barrière linguistique favorisaient le maintien des usages locaux, la supériorité technique du droit romain, l'action souple des constitutions impériales, qui légiféraient pour les provinces comme pour la vieille Romie, les édits des gouverneurs de province ${ }^{20}$ servaient la pénétration progressive du droit romain ${ }^{21}$.

Celle-ci apparait parfois maladroite, dans l'insertion de clauses mal transcrites et donc incomprises ${ }^{22}$. Au traditionalisme évoqué plus haut répond ici une volonté de paraître romain, quelquefois maladroite. Peu à peu cependant le droit romain, surtout dans les domaines techniques, moins sensibles aux réactions affectives, tendit à se généraliser ${ }^{23}$.

17 Voir par exemple R. Ta ubenschlag, The Roman authorities and the local law in Egypt before and after the C. A., JJP, V (1951) 121-141.

18 C'est ainsi que l',,affranchissement sacral", inconnu du droit romain, persiste en Orient au IIIe siècle (Nörr, Bemerkungen zur sakralen Freilassung, Studi... Volterra, II, Milano 1969, 619 sq). Certains romanistes ont cependant soutenu que les nouveaux citoyens de la constitution de Caracalla étaient obligés de recourir au droit romain (Sic Amelotti, Il testamento romano, Firenze 1966, $224-225)$.

${ }_{19} \mathrm{Cf}$. par exemple E. Volter ra, L'adozione testamentaria ed un iscrizione latina e neopunica delle Tripolitana, Atti Acc. Lincei, 1952, 175-188; W. S e 1 b, Reichsrecht und lokale Eheschliessungsformen in den röm. Ostprovinzen, JJP, XV (1965) 99-118, montre, d'après le Coutumier syro-romain la persistance des usages locaux après 212. Toutefois J. Modrzeje wski (La régle de droit dans l'Egypte romaine, Rapport au XIIe Congrès de Papyrologie, 1968) a montré que ,paradoxalement" en Egypte la romanisation du droit familial et successoral fut plus rapide et plus profonde que celle du droit des affaires.

20 H. K u piszew ski, Röm. Provinzialrecht in Aegypten, Festschrift Oertel, Bonn 1964, 68-80.

21 J. M o drze je w s k i, op. cit.

22 D. Simon, Studien zur Praxis der Stipulations-Klausel, Münch. Beiträge zur Papyrusforschung 48, München 1964; E. P ol a y, Die Zeichen der Wechselwirkungen zwischen dem röm. Reichsrecht und dem Peregrinenrecht im Urkundenmaterial der siebenbürgischen Wachstafeln, ZSS. Rom. Abt. 1962, 51-85.

23 Sur la romanisation du droit des contrats, cf. H. J. W olff, Zur Romanisierung des Vertragsrechts der Papyri, ZZS. Rom. Abt. 1956, 1-26. 
2. A côté de cette acceptation individuelle, plus ou moins accusée et plus ou moins rapide, la rencontre du droit romain et des droits locaux droit être envisagée dans un cadre plus général, que l'on ne saurait cependant sans quelque abus qualifier de ,législatif”. Du moins la législation impériale en porte-t-elle la marque. Sur certains points elle dut s'opposer formellement à des usages locaux qui répugnaient à la morale romaine, par exemple aux mariages entre frères et soeurs en Egypte 24. Plus largement dans plusieurs constitutions Dioclétien s'efforce de repouser des tentatives de pénétration de pratiques provinciales dans le droit romain ${ }^{25}$. Par la suite cette défense fut moins bien assurée. Certains usages locaux pénétrèrent au cours de l'âge post-classique dans le droit des constitutions impériales ${ }^{26}$ et plus encore sans doute contaminèrent le droit romain dans la pratique courante ${ }^{27}$. Il n'en demeure pas moins que la législation impériale depuis le $\mathrm{II}^{\mathrm{e}}$ siècle concerne les provinces autant sinon plus que la vieille Rome. Ses destinataires sont, non seulement les fonctionnaires impériaux en poste dans les provinces, mais bien souvent des communautés locales. Innombrables sont aussi les rescrits adressés à des particuliers, dont on ignore bien sûr la condition et le domicile. Mais leur nom dénonce leur origine provinciale, souvent orientale ou hellénique et lorsqu'ils s'appellent Aurelii, il s'agit en général des bénéficiaires de la concession du droit de cité par Caracalla ou de leurs descendants.

Ce n'est donc pas la volonté du vainqueur qui a imposé le droit romain à l'Empire. Certes, sans la conquête, il serait resté celui de la seule Rome. Mais la conquête n'a fait qu'offrir un champ d'application. Elle n'a rien imposé

24 J. Modrzejewski, Die Geschwisterehe in der hellen. Praxis und nach röm. Recht, ZZS. Rom. Abt. 1964, 73-80; autres exemples donnés par Y a r o n, Reichsrecht, Volksrecht und Talmud, RIDA XI (1964) 281-298.

25 E. S ch ön b a u r, Diokletian in einem verzweifelten Abwehrkampfe, ZZS. Rom. Abt. 1952, 267-346; M. A m e lot ti, Per l'interpretazione della legislazione privatistica di Diocleziano, Milano 1960, 72 sq.

${ }_{26}$ La mesure de cette pénétration est très difficile à apprécier. On eut, voici quelque quarante ans, tendance à l'admettre assez largement et peut-être a-t-on surestimé la part des usages orientaux ou hellénistiques dans le droit post-classique (cf. en particulier E. Carusi); voir sur cette question E. Volter r a, Diritto romano e diritto orientali, Bologna 1937; Introduction à l'histoire du droit romain dans ses rapports avec l'Orient, Arch. d'hist. du droit oriental, IV (1949) 117-159; R. Ta ubenschlag, Der Einfluss der Provinzialrechte auf das römische Privatrecht, Atti del Congr. Intern. di D. R., Roma 1935, I, 281-316 = Opera minora 421-460; J. Mo d r z e j e w s ki, Loi et coutume dans l'Egypte grecque et romaine: Recherches sur les facteurs de formation du droit privé en Egypte au temps des Lagides et sous la domination romaine (Thèse de droit, Paris 1970); M. A m elott i, L'epigrafe di Pergama sugli AETYNOMOI e il problema della recezione di leggi straniere nell'ordinamento giuridico romano, SDHI XXIV (1958) 80-111 envisage des exemples de cette réception de lois étrangères dès l'époque classique et E. Ferenczy, Fremde Einflüsse auf die Rechtsentwicklung der klassischen Republik, RIDA XVIII (1971) 501-523 en signale dès la période 367-146 av. notre ère. 
Les vraises causes sont ailleurs. L'une, d'abord, est juridique: c'est la concession généreuse et massive de la qualité de citoyen, condition d'accès au ius civile. Mais là encore il ne s'agissait que de l'ouverture d'une possibilité. Si les provinciaux en firent usage et de plus en plus largement, c'est peut-être en partie par suite du prestige qu'exerçait Rome et tout ce qui venait d'elle, civilisation, culture, droit. Mais c'est surtout parce que ce droit parut supérieur en pratique aux divers droits locaux. Sa connaissance n'était cependant pas aisée. L'enseignement juridique fut longtemps à Rome affaire privée, relation de patron à disciples, sans qu'il y ait d'écoles de droit. Celles-ci n'apparaissent qu'au Bas-Empire et leur nombre resta toujours relativement faible. Comment se formèrent les praticiens locaux? On ne le sait guère et cependant la technique du droit romain était souvent subtile. Ce qui explique les erreurs juridiques dont témoignent beaucoup d'actes. Mais, malgré ces difficultés et ces faux pas, le droit romain fut appliqué de la Frise à l'Egypte, de l'Espagne à la Syrie, de la Bretagne à l'Afrique du Nord.

\section{II - L'OCCIDENT MEDIÉVAL}

La diffusion du droit romain par les Universités

C'est un tout autre exemple qu'offre l'Occident médiéval bien que l'on retrouve une fois encore la diffusion du droit romain et son adoption par des sociétés pour lesquelles il n'avait pu être fait. Il s'agit de cet évènement capital de l'histoire de l'Occident désigné globalement sous le terme de ,réception du droit romain".

Sous réserve de certaines persistances du droit théodosien dues surtout à la diffusion du Bréviaire d'Alaric et d'éléments de la tradition juridique romaine conservés par l'Eglise ${ }^{28}$, le droit romain avait depuis la fin du $\mathrm{V}^{\mathrm{e}}$ siècle cédé la place aux coutumes locales.

C'est vers 1050-1070, dans des conditions dont l'obscurité a laissé libre cours aux légendes, que le Digeste fut „retrouvé” en Italie. Le Code et les Institutes n'avaient jamais cessé d'être connus, sinon bien utilisés.

La supériorité de la compilation justinienne sur les coutumes locales était telle qu'elle suscita aussitôt des études enthousiastes, au moment où naissaient les Universités. Bologne, qui devait rester longtemps la plus importante école de droit d'Occident, connaît l'enseignement de

${ }_{27}$ C'est le problème du ,droit vulgaire" qui fait depuis vingt ans l'objet d'amples débats.

28 Nous avons tenté de les cerner dans deux études: Survivances romaines dans le droit de la Monarchie franque du Ve au Xe siècle, Tijdschrift voor Rechtsgeschiedenis, XXIII (1953) 149-206; Le droit romain dans la pratique et chez les Docteurs aux XIe et XIIe s., Cahiers de civilisation médiévale, VIII (1965) 365-380. 
Pepo au dernier quart du $\mathrm{XI}^{\mathrm{e}}$ siècle et s'affirme avec éclat dans les années 1120 avec Irnerius.

De ce premier foyer le droit romain gagne en quelques siècles tout l'Occident. De nombreux travaux tentent, depuis quelques décades, de suivre ce mouvement, d'en préciser les dates, les voies, les forces d'impulsion ${ }^{29}$. L'enquête est loin d'être achevée. Les moyens d'investigation ne sont d'ailleurs pas les mêmes dans tous les pays, ce qui entraîne souvent des différences dans les méthodes et finalement un manque d'homogénéité dans les résultats.

C'est ainsi que les historiens français, servis par une documentation abondante mais qu'il faut presque toujours aller chercher dans les fonds d'archives notariales manuscrites, se sont efforcés de relever avec précision les dates des premières manifestations du droit romain dans les actes de la pratique. Pour les autres pays des enquêtes de ce genre sont exceptionnelles. Ce sont plus souvent les oeuvres doctrinales, voire les textes législatifs qui sont allégués. De telles différences dans l'enquête obligent à n'esquisser qu'avec beaucoup de prudence un exposé qui se voudrait de synthèse ${ }^{30}$.

En $\mathrm{France}$, ce sont les régions méridionales qui témoignent les premières d'une influence du droit romain retrouvé. A. Gouron a relevé des signes de cette pénétration sur le littoral méditerranéen entre Arles et Narbonne dès le milieu du XII ${ }^{e}$ siècle ${ }^{31}$, alors que la région niçoise qui se rattache à la zone d'influence de Gênes, a, comme les villes d'Italie $\mathrm{du}$ Nord, des notaires dès le milieu du XI $\mathrm{XI}^{\mathrm{e}}$ siècle ${ }^{32}$. Mais le littoral provençal ne sera atteint que plus tard ${ }^{33}$. Le droit romain apparaîtrait dans les actes en latin du Rouergue vers $1150-1160^{34 ;}$ dans la région toulou-

29 On trouvera dans l'orientation bibliographique donnée à la fin de cette étude l'indication de quelques-uns d'entre eux.

30 Nous laisserons cependant hors de notre exposé les îles britaniques, les pays scandinaves, la péninsule ibérique et l'Italie. Pour des raisons différentes, la situation du droit romain dans ces pays fut en effet très particulière. Quant aux pays slaves du Sud, ils connurent le droit romain par l'Eclogue byzantin qui présentait déjà d'importantes différences avec la compilation justinienne. L'Eclogue alave en différe encore davantage. Mais ce droit écrit fut mal connu des praticiens. L'absence d'école de droit rendait précaire toute formation juridique. Aussi le droit coutumier conserva-t-il la place essentielle (cf. M. André ev, Acta iuridica XVII, 1970, 9-13).

31 Diffusion des Consulats et expansion du droit romain, 58.

32 Ibid. 56. A Montepellier ils ne sont pas attestés avant 1139 (57).

33 Melle $\mathrm{Ca} \mathrm{r} l \mathrm{in}$ (La pénétration du droit romain dans les actes et la pratique provencale XI-XII e s.) constate aussi une sorte de ,vide entre la Ligurie et la Septimanie" qu'elle impute à la moindre activité économique de la région.

${ }_{34} \mathrm{P}$. O url i a c (Note sur les actes rouergats...) fait observer que, si les actes rédigés en latin témoignent ,de la griserie d'une leçon récemment apprise”, ceux en langue vulgaire ne portent aucune marque romaine au XIIe s. Les renonciations aux privilèges romains n'apparaissent pas dans ce type d'acte avant 1210 et elles ne se multiplient qu'au milieu du XIIIe s. 
saine, la Provence et la vallée du Rhône dans la seconde moitié du XII siècle; dans le Quercy, le Périgord, le Limousin, l'Auvergne et le Forez, vers la fin du XIIIe 35 .

Ainsi l'influence du droit romain se serait fait sentir en Septimanie avant la venue de Rogerius ${ }^{36}$ et avant que Placentin ne soit accueilli à Montpelier entre 1161 et 1170. L'arrivée des Bolonais aurait provoqué „,non un accroissement de la pénétration, mais bien un mouvement général de renonciation" ${ }^{37}$. E. Meynial avait déjà souligné cette résistance de la population à l'égard de principes juridiques étrangers ${ }^{38}$. Et A. Gouron suggère alors pour le $\mathrm{XII}^{\mathrm{e}}$ s. une ligne assez sinueuse: Après un timide essai de pénétration, tenté par les praticiens dès le premier tiers du siècle et qu'expliqueraient les relations commerciales avec l'Italie du Nord, le droit romain eonnaît une grande faveur au milieu du XII s. avant que, dans les trente dernières années du siècle, de nouvelles techniques (les renonciations) n'en viennent limiter la portée ${ }^{39}$.

Ces premières infiltration romaines ne sauraient en effet être mises au compte d'un enseignement juridique. Il n'existe pas dans le Midi de la France d'Université au XII ${ }^{\mathrm{e}}$ siècle. Montpellier, célèbre par son

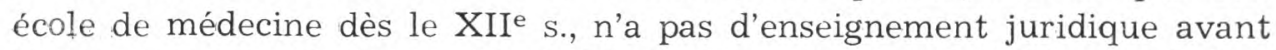
la fin du siècle. L'Université de Toulouse est créée en 1229 pour lutter contre l'hérésie albigeoise.

C'est donc très probablement à l'influence des marchands et des relations commerciales avec l'Italie qu'il faut attribuer cette pénétration encore modeste des notions romaines. D'où leur premier accueil sur le littoral entre Rhône et Aude, point d'arrivée des navires italier.s, puis ultérieurement leur progression selon deux axes différents: vers Toulouse et le long du sillon rhodanien ${ }^{40}$.

Mais la portée exacte de ces premiers témoignages reste discutée et l'on a pu contester l'importance d'une véritable pénétration du droit romain dans le Midi de la France avant le XIII s. Les magistri et les iudices du milieu du XII ${ }^{\mathrm{e}} \mathrm{s}$. n'ont pas l'importance décisives des légistes du XIII'. L'action de ces derniers est nette en Languedoc vers 1230. Au

35 A. Gouron, op. cit., 58-64. Les critères retenus pour fixer cette chronologie de la pénétration sont, en plus du vocabulaire, l'existence d'un notariat public et la pratique du, ,serment à la bolonaise".

36 Qui plaide en 1162 pour Hugues des Baux.

37 A. Gouron, Les étapes de la pénétration..., 104.

38 De l'application du droit romain dans la région de Montpellier aux XIIe et XIIIe s., Atti Cong. intern. Sc. storiche, Rome 1904, t. IX, 150.

39 (1p. cit., 108; J. Hilaire (Les régimes matrimoniaux aux XIe et XIIe s. dans récion de Montpellier, Rec. de Mém. et Trav. de la Soc. d'hist. du droit des pays de droit écrit, III, i955, 17) a montré la pénétration au cours du XIIe siècle de la dot de type romain accompagnée d'une donatio propter nuptias faite par le mari.

40 A. Gouro $\mathrm{n}$, Commerce et diffusion du droit romain, Etudes... à la mémoire de H. Cabrillac, Paris 1968, 205-217. 
milieu du siècle elle devient essentielle ${ }^{41}$. Le droit romain est largement utilisé pour mettre au point la prucédure d'Inquisition dirigée contre les Albigeois. A partir du milieu du XIII ${ }^{\mathrm{e}}$ s. les juristes formés aux disciplines romaines peuplent l'administration et les Tribunaux. La Coutume de Toulouse de $1286^{42}$ porte la marque de cette influence romaine ${ }^{43}$. L'étude de la réception du droit romain a été faite à un autre point de vue et pour une autre région de la France, la Bretagne et l'Anjou, par J. Ph. Lévy ${ }^{44}$. L'enquête ici n'a pas porté sur les actes de la pratique. mais sur les livres de droit, les coutumiers des XIII et XIVe siècles ${ }^{45}$.

En Anjou la Compilatio de usibus et constitutionibus Andegavie et des Coustumes d'Anyou et dou Maigne du XIII ${ }^{\mathrm{e}}$ s. $^{46}$ témoignent déjà de connaissance juridiques romaines, non dans le plan des compilations, mais par des emprunts de terminologie, des citations ou des traduction de passages de la compilation justinienne. Les emprunts terminologiques, timides au XIII $\mathrm{s}$., sont considérables dès le début du XIVe. La très ancienne coutume de Bretagne rédigée au début du XIVe s. est plus. marquée par le droit romain que la Compilatio angevine du XIII ${ }^{47}$. Cependant jusqu'à la fin du XIVe $\mathrm{s}$. la réception du droit romain est limitée et de borne souvent à des emprunts formels. L'essor se produit dans la première moitié du $\mathrm{XV}^{\mathrm{e}}$ siècle. Les ordonnances des ducs de Bretagne et les documents coutumiers de l'Anjou témoignent alors de cette pénétration romaine. Mais le milieu du siècle est marqué par ,un net coup d'arrêt" 48 et le droit de l'Ouest de la France restera essentiellement coutumier et féodal.

41 Quitte à provoquer les doléances et les critiques amères des poètes, $\mathrm{P}$. O u rI i a c (Troubadours et juristes, Cahiers de civilisation médiévale, VIII, 1965, 159177) a montré l'opposition des troubadours à la rigueur des solutions romaines. Clivage idéologique, mais qui laisse soupçonner les nuances sociales qu'il faudrait introduire.

${ }_{42}$ H. Gilles, Les Coutumes de Toulouse (1286) et leur premier commentaire (1926), 1968.

${ }_{43} \mathrm{P}$. O u r I i a c, La société languedocienne du XIIIe siècle et le droit romain, Cahiers de Fanjeaux, 6, 199-216.

${ }_{44}$ La pénétration du droit savant dans les coutumiers angevins et bretons au Moyen-Age, Tijdschrift voor Rechtgeschiedenis, XXV (1957) 2-53; La pénétration. du droit privé savant dans le „Vieux Coustumier de Poitou”, Mél. P. Petot, Paris 1958, 371-383.

45 Le nombre important des manuscrits de la compilation justinienne et de ses interprétes médiévaux (Accurse, Azon, Bartole, Cynus etc.) prouve l'intérêt que suscitait le droit romain de la Normandie à la Touraine. La plupart d'entre eux appartenaient à des bibliothèques monastiques (Mont Saint Michel, Jumièges, Marmoutiers, Saint Aubin, Sairt Gatien de Tours etc). Leur rôle ne se bornait pas sans doute à servir une curiosité érudite. Ils étaient utilisés par les praticiens et servirent.peut-être à l'enseignement (cf. J. Br é jon de Laverg né e, La pénétration du droit romain dans les pays de l'Ouest de la France. Rec. de Mém. et Trav. de la Soc. d'hist. du droit des pays de droit écrit, VI, 1967, 57-59).

${ }_{46}$ Editées par B e a t e mps-Be a u pré: coutumes et institutions de l'Anjou et du Maine antérieures au XVIe s., T. I, p. $41-62$ et $63-176$.

${ }_{47}$ J. Ph. L é v y, T. R., 1957, 24.

48 Op. cit., 4. 
Dans l'Est de la France le XIII ${ }^{e}$ s. est aussi celui de la pénétration romaine. Dans le Comté de Bourgogne elle n'apparait pas avant 1230 . Modeste de 1230 à 1250 , elle triomphe dans le dernier tiers du XIII siècle ${ }^{49}$.

C'est au XIII ${ }^{\mathrm{e}} \mathrm{s}^{50}$ également que des légistes formés au droit romain apparaissent en Flandre dans l'entourage des Comtes et dans les instances administratives et judiciaires des villes ${ }^{51}$. Des clauses de renonciation au bénéfice du droit romain dans les actes privés attestent, par a contrario, la connaissance de ce droit, les essais de l'imposer et aussi les résistances de la pratique à son introduction ${ }^{52}$.

En Frise, à la même époque, ce sont presque uniquement des clercs qui font connaître et parfois accepter des solutions romaines. L'Eglise en effet a toujours prétendu vivre ,sous la loi romaine” et, en fait, pour des raisons multiples ${ }^{53}$, le droit romain a largement marqué la technique et les institutions canoniques. Et c'est bien souvent par le canal du droit canonique et par l'action des clercs que le droit romain pénétra les droits coutumiers locaux. On a également des exemples de la pénétration romaine dans la province d'Utrecht au XIVe siècle, mais on manque d'études pour les autres régions des Pays-Bas.

49 G. Chevrier, Les étapes de la pénétration du droit romain dans le Comté de Bourgogne au XIIIe s., Mém. Soc. hist. du droit... des pays bourguignons..., XIX (1957) $37-43$.

5n Un ouvrage de référence, le Liber Floridus, composé vers 1120 dans le sud du Comté de Flandre, prouve que la compilation justinienne n'y est pas encore connue (F. L. G a n s of, Droit romain dans le „Liber Floridus”, T. R. XXIX, 1961, $432-444)$.

51 J. Gilissen, Les légistes en Flandre aux XIIIe et XIVe s., Bull. Comm. roya?e des anc. lois et ord. de Belgique, XV (1939) 117-231.

52 J. Giliss en, L'apparition des renonciations aux exceptions du droit romain dans le droit flamand au XIIIe s., Mél. F. de Visscher, III = RIDA IV (1950) $513-550$

L'étude des clauses de renonciation est précieuse pour déterminer l'époque de pénétration du droit romain dans une région et pour apprécier les résistances auxquelles il se heurta. Elle a été entreprise par E. M e y nial, qui a ouvert la voie aux enquetes dans ses études, Des renonciations au Moyen-Age et dans notre droit, NRHD $1900,108-143 ; 1901,241-277 ; 657-697 ; 1902,49-78 ; 649-710 ; 1904$, 698-748 et La réaction populaire contre l'invasion du droit romain en France aux XIIe et XIIIe s., Mél. Chabaneau, Erlangen 1906, 557-584. Parmi les travaux sur ce sujet on pourra consulter: J. Yver, Les contrats dans le très ancien droit normand, Th. Caen 1926, 37 sq; M. C a staing-S i a r d, Les contrats dans le très ancien droit toulousain, Th. Toulouse 1959, 528-564; A. G o u r o n, Etapes de la pénétration, 116-118; F. V e r c a t e re n, Note sur l'apparition des renonciations aux exceptions $d u$ droit romain dans les principautés belges au XIIIe s., Etudes... Didier, Grenoble 1960, 325 sq; J. G a y, Les clauses de renonciations au XIIIe s. dans la partie méridionale du Comté de Bourgogne, Mém. soc. hist. du droit... des pays bourguignons, XXI (1960) 63-90; Y. J e a n c 1 os, Les renonciations au XIIIe s. d'après quelques cartulaires champenois, Mém. soc. hist. du droit... des pays bourguignons, XXIX (1968-1969) 437-454.

${ }_{53}$ Vieille tradition remontant aux IVe et Ve siècle lorsque l'Eglise se développait dans l'Empire romain; meilleure conservation à Rome des traditions romaines; large usage du droit romain par les réformateurs grégoriens au XIe s. puis par les clercs savant des XIIe-XIIIe $\mathrm{s}$. 
A Malines le droit romain s'impose dans la seconde moitié du XV et au XVI ${ }^{e}$ s. C'est ici l'influence du Grand Conseil de Malines, créé en 1473 pour les Etats bourguignons, et, au début du XVIe, celle de la Cour humaniste de Marguerite d'Autriche. L'essor du droit romain au XVe s. est l'oeuvre de juristes, formée dans les Universités, qui peuplent les juridicions provinciales et les services de l'état bourguignon ${ }^{54}$. D'autre part des coutumes rédigées aux $\mathrm{XV}^{\mathrm{e}}$ et au XVI ${ }^{\mathrm{e}} \mathrm{s}$. en font un droit subsidiaire, peut-être par imitation de la solution adoptée par le Coutume du Duché de Bourgogne. Ces rédactions furent cependant peu nombreuses. Mais, même en l'absence d'une clause expresse, les juristes se réfèrent de plus en plus au droit romain en cas d'insuffisance de la coutume.

La réception du droit romain fut plus limitée dans les provinces du Sud (actuelle Belgique), peut-être parce qu'une rédaction plus précoce des coutumes bloqua l'infiltration du droit romain. Mais, là où elle eut lieu, cette réception se fit par le relai de la France, soit que des clercs des Pays-Bas soient venus se former à l'Université d'Orléans (où ils furent nombreux), soit que les institutions judiciaires françaises aient servi de modèle, à l'époque de la domination bourguignonne.

E n Allem a g ne, où le droit romain jouera un rôle primodial du XVI ${ }^{\mathrm{e}}$ siècle jusqu'à la promulgation du $\mathrm{BGB}^{55}$ de 1900 , l'étude de la réception a fait l'objet de nombreuses enquêtes. La notion même de „réception" y fut d'ailleurs controversée. Les Pandectistes du XIX ${ }^{\mathrm{e}}$ s. entendaient sous ce terme l'application subsidiaire du droit romain par les tribunaux séculiers depuis le début du XVIe siècle, ce droit romain étant celui de la compilation justinienne vue à travers l'interprétation des glossateurs (le „droit commun”). Mais H. Coing a bien montré qu'historiquement la réception avait été précédée d'une ,pré-réception”, qui commence vers 1250 et par conséquent la vraie période de la réception s'étend de 1250 à 1550 .

L'étude de ce phénomène d'histoire juridique n'a pas toujours été menée dans un esprit de parfaite objectivité. Au nom du germanisme, certains historiens allemands du XIXe $\mathrm{s}$. tendaient à le minimiser ou à opposer coutumes populaires et droit savant des clercs ${ }^{56}$. Plus près de nous, le National-socialisme s'en est pris à la réception du droit romain qui avait introduit un droit étranger à l'esprit germanique et de surcroit juif et capitaliste ${ }^{57}$.

Plus importants pour nous sont les résultats d'enquêtes historiques,

54 R. Feenstra, Zur Rezeption in den Niederlanden, St. Koschaker, I, 262. scheid.

55 Qui a été profondément marqué par l'influence du grand romaniste Wind-

56 Par exemple B e s eler, Volksrecht und Juristenrecht, 1843.

57 W. M e r k, Vom Werden und Wesen des deutschen Rechts, 1935. 
le plus souvent limitées à une région ou à une ville, mais qui permettent de jalonner les étapes de la réception et d'en déterminer les causes.

La continuité affirmée entre l'Empire romain et le Saint Empire romain germanique aurait pu servir la réception du droit romain. Ce serait l'argument ,politique". Et l'on sait que dans d'autres pays, comme la France, la Hongrie ou la Pologne, cet argument a joué contre le droit romain, du moins contre une réception trop officielle qui aurait pu passer pour une reconnaissance de la supériorité politique de l'empereur sur les rois.

En fait cet argument politique n'a pas servi la réception du droit romain en Allemagne ${ }^{58}$. Les empereurs germaniques, qui se posaient en successeurs des empereurs romains, n'ont pas exercé une influence profonde sur l'évolution du droit en Allemagne au XIII ${ }^{\mathrm{e}}$ siècle. Ni la théorie de la translatio imperii, ni celle de la renovatio imperii ne sont alléguées pour justifier les emprunts au droit romain. La législation impériale n'est pas profondément marquée par le droit romain 59 .

$\mathrm{Si}$ la pseudo-continuité politique n'entre pas en ligne de compte, peut-être faudrait-il être plus prudent en ce qui concerne l'action possible d'une notion „,culturelle”, celle de l'idéal que représentait pour beaucoup l'image de la vieille Rome. Cette „Kulturelle Romïdee”, le prestige des souvenirs romains n'ont pu que favoriser l'acceptation du droit romain.

A la différence de ce qui s'est fait en France, les études sur la réception du droit romain en Allemagne n'ont guère porté sur les actes de la pratique ${ }^{60}$. Celle des sources littéraires n'est qu'à ses débuts. Le rayonnement des officialistés hors de l'Eglise n'a pas été abordé. La recension des manuscrits de droit romain, à laquelle Seckel avait consacré de longues recherches, est loin d'être achevée ${ }^{61}$.

Aussi est-ce, dans une large mesure, sous la forme de l'introduction d'une science juridique qu'apparaît, dans l'état actuel de nos connaissances, la réception du droit romain en Allemagne ${ }^{62}$. Le rôle des tribunaux et celui des docteurs ont été tout particulièrement soulignés. Les

58 Telle est l'opinion soutenue par Krause, Coing et, pour les Pays-Bas par R. Feenstra, reprise et fortement affirmée par Winfried T r us e n, Zur Rezeption des röm. Rechts in Deutschland, Acta iuridica, XVII (1970) spéc. 127.

59 Les emprunts sont souvent formels, tels lex animata (Nov. 105, 2, 4) qui apparaît depuis 1230 dans des constitutions impériales.

60 Indication de H. C o ing, Röm. Recht in Deutschland, IRMAE V, 6 (1964) $116-136$.

${ }_{61}$ Ces déficiences sont signalées par H. Coing, Eindringen des römisches Rechts in das Recht des Hochmittelalters in Deutschland, Düsseldorf 1955, 4. Le dernier exposé systématique des sources remonte à 1859 ( $\mathrm{S} \mathrm{c} \mathrm{h} \mathrm{äffer,} \mathrm{Das} \mathrm{römische}$ Recht in Deutschland während des 12. und 13. Jahrhunderts, Erlangen).

62 Telle était déjà l'opinion de Sohm, reprise par F. Wieacker qui parle d'un „Verwissenschaftlichung”. 
premiers à faire connaître le droit romain et à l'utiliser furent des clercs, prédécesseurs des „légistes” dans l'administration séculière ou membres des tribunaux ecclésiastiques.

A) Déjà Frédéric I, lors de la Diète de Roncaglia, avait fait appel aux romanistes pour fortifier ses droits. Dans leur lutte séculaire contre la papauté, les empereurs utilisèrent les services des clercs, savants, qui trouvèrent dans la compilation justinienne les textes propres à assurer l'autorité impériale ${ }^{63}$.

La diffusion de solutions romaines par l'intermédiaire des tribunaux ecclésiastiques fut importante, encore qu'il soit difficile d'en apprécier exactement la mesure. Le développement des officialités avec une procédure savante, romano-canonique, favorisa ce mouvement. De jeunes allemands s'initièrent au droit romain à Bologne et plus tard à Padoue. Dès 1265 l'Université de Bologne compte une „Nation germanique”. Mais ce n'est guère qu'à la fin du XIVe siècle que des Universités sont créées dans l'Empire ${ }^{64}$, facilitant ainsi l'étude du droit romain. Il ne faut d'ailleurs pas oublier que la place faite au droit romain dans ces Universités fut moindre que celle du droit canonique.

Les compilations juridiques du XIII ${ }^{\mathrm{s}}$ s. n'accordent guère de crédit au droit romain. Le „Saxenspiegel”, qui codifie le droit saxon des diocèses de Magdebourg et d'Halberstadt vers 1220 - 1235, utilise le droit canonique, mais très peu le droit romain. Le „Schwabenspiegel”, oeuvre d'un clercs d'Augsbourg de 1274/75, témoigne déjà d'une plus forte influence romano-canonique. Dans les „Landrechte” et „Stadrechte” du $\mathrm{XIII}^{\mathrm{e}}$ s., le droit romain compte peu, si ce n'est pour combler certaines lacunes des droits locaux.

$\mathrm{Au} \mathrm{XIV}^{\mathrm{e}}$ s., en l'absence d'Université en Allemagne, la littérature savante n'existe guère. Toutefois la connaissance du droit romain est attestée par un répertoire alphabétique la Tabula iuris canonici et civilis de Jean de Saxe, composée en Italie au début du XIVe $\mathbf{s}$. ou par la glose du Sachsenspiegel d'un ancien étudiant de Bologne, Johann von Buch (après 1235). L'importance de cette glose est grande, car elle servira la pénétration dans les droits locaux du droit romain et du droit canonique.

Quant aux actes juridiques, en l'absence d'un notariat spécialisé qui ne s'introduisit en Allemagne que tardivement, ils sont rédigés par des personnes d'instruction très inégale. D'où la grande inégalité de leur valeur juridique. Des expressions, voire des formules romaines apparaissent dans les actes au milieu du XIII ${ }^{\mathrm{e}}$ siècle; elles se multipient à partir de la

63 Cf. Jean d'Os na br ü ck, De prerogativa romani imperii (1251-1281); Alexandre de $\mathrm{R}$ o es, Tractatus de translatione imperii (1281); Lupold de $\mathrm{B}$ obe nb u r g, Tractatus de iuribus regni et imperii (1340).

${ }_{64} \mathrm{Si}$ l'on excepte Prague (1348), les créations son tardives: Heidelberg 1387, Erfurt 1392, Cologne 1388. Elles se multiplient au XVe siècle. 
fin du siècle. La résistance à cette pénétration romaine est prouvée par les clauses de renonciation, qui apparaissent dès $1256^{65}$ et se multiplient depuis 1280 .

Mais il ne faudrait pas voir là, comme on a parfois tenté de le faire, une opposition populaire délibérée défendant les usages germaniques contre un droit étranger imposé. Si la littérature s'en prend aux ,juristes", c'est our dénoncer un groupe social qui menace les privilèges des nobles, qui coute cher aux bourgeois, qui sert les princes, non pour condamner le droit romain qu'il utilise ${ }^{66}$. C'est la révolte contre les contraintes des états naissants auxquels les légistes pretent leur service et leur science. C'est aussi la critique des frais qu'entraine la procédure romano-canonique, écrite et plus complexe. Et, si parfois une règle coutumière est défendue contre le droit romain, c'est au nom de la tradition plus que d'un droit germanique qui n'existe guère ${ }^{67}$.

B) A ce qui n'avait été que manifestation limitées de l'influence romaine succède, à partir du $\mathrm{XV}^{\mathrm{e}}$ siècle et surtout depuis la fin du siècle, une „réception” beaucoup plus importante. Les causes en sont multiples.

1. D'abord le développement des Universités allemandes ${ }^{68}$ qui sont les foyers auxquels viennent se former juges et administrateurs. Le droit romain y gagne du terrain sur le droit canonique. A la fin du $\mathrm{XV}^{\mathrm{e}} \mathrm{s}$., il est enseigné dans toute les Universités. Cette prépondérance ne fera que s'accentuer avec les Universités créées après la Réforme ${ }^{69}$, Luther ayant marqué sa répugnance pour le droit canonique.

Le droit romain est présenté comme le ius commune de l'Empire germanique, successeur de Rome, alors que le droit local, trop morcellé et trop divers pour pouvoir être tenu pour droit „,national allemand”, est réduit à un rôle subalterne. Les juristes le traitent volontiers comme les statuts des villes italiennes. Nombreux sont d'ailleurs les juristes allemands qui, ayant fait leurs études dans des Universités italiennes, connaissent mal le droit local germanique ${ }^{70}$.

2. Instruits par les Universités, les juristes propagent les solutions romaines dans les tribunaux ${ }^{71}$. Dès le XIII ${ }^{\mathrm{e}} \mathrm{s}$. le droit romain avait été largement utilisé par les juridictions ecclésiastiques. La compétence de celles-ci dépassait de beaucoup les questions strictement religieuses. Aussi

65 H. C o ing, Eindringen..., 15.

66 H. Thieme, Le rôle des ,doctores legum" dans la societé de l'Allemagne du XVIe s., Rec. de Mém. et Trav. de la Soc. d'hist. du droit des pays de droit écrit, VI (1967) 47-48.

${ }_{67} \mathrm{H}$. C o in g, Pre-recezione, passim.

68 Tübingen - 1476, Mayence - 1478, Francfort sur l'Oder - 1506 etc.

69 Marbourg - 1527, Königsberg - 1544, Iena - 1558.

70 H. Th i e m e, op. cit., $45-47$.

${ }^{\prime}$ On ne saurait méconnaître le rôle de la doctrine et des oeuvres juridiques; cf. par exemple pour les Decisiones de Johann Köppen (1531-1611) J. M. S c h o l z, Der branderburgische Landrechtsentwurf von 1594, Köln 1973. 
était-ce déjà un vaste domaine qui subissait l'influence romaine. Dans la seconde moitié $d u X^{e}$ s. les juridictions laiques adoptent la procédure romano-canonique. Mais ce ne sont pas seulement les formes procédurales qui reprennent les traditions romaines. Le droit appliqué par les juges, formés au droit romain, est très largement romain. Appliquant la maxime de Balde ubi cessat statutum habet locum ius civile ${ }^{72}$, ils accordent au droit romain un rôle subsidiaire, en cas d'insuffisance du droit local.

La Reichskammergericht, créée à Francfort en $1495^{73}$, juge selon la procédure romano-canonique et applique ,le droit écrit commun de l'Empire". Les cours inférieures peu à peu se rallient au droit romain.

3. Cette primauté du droit romain sur les coutumes locales ne tient pas seulement à sa supériorité technique. Des raisons plus contingentes desservaient les coutumes. D'abord la difficulté d'en établir le contenu et de les prouver. Et le juge, qui souvent connaissait mieux le droit romain, pouvait se réfugier derrière l'insuffisance de preuves pour écarter la coutume. Là où la coutume locale était écrite, elle se défendait mieux.

Une autre objection pouvait être faite à la coutume. Après le droit romain tardif, le droit canonique avait exigé qu'elle fut „raisonnable”. Les „Commentateurs”, plus que les Glossateurs ont insisté sur cette exigence. Or il appartenait au juge de se prononcer sur cette rationabilitas. La refuser offrait un nouveau moyen d'écarter la coutume ${ }^{74}$.

4. Favorisé au degré de l'Empire par la jurisprudence du Reichskammergericht, le droit romain pénétra aussi dans les principautés locales et les villes libres. Les princes, comme l'empereur, mirent en place à partir de la fin du $\mathrm{XV}^{\mathrm{e}} \mathrm{s}$. des organes administratifs et des tribunaux qu'ils confièrent à un personnel de juristes savants. Cette substitution d'un pouvoir politique moderne aux seigneuries médiévales servit le droit romain. Dans les villes libres au contraire les tribunaux restèrent aux mains du patriciat et ce furent les plaideurs et leurs avocats qui vulgarisèrent l'usage du droit romain. Celui ci passa dans la législation du pays et des villes, rédigée depuis le milieu du XV $\mathrm{XV}^{\mathrm{e}} \mathrm{s}$. et au cours du XVI . Ce mouvement législatif, désigné sous le nom de „Réforme" ${ }^{75}$, marque une nouvelle victoire du droit romain.

Elément d'unité juridique en face de la multiplicité des „Land-" et des „Stadrechte”, tenu pour source subsidiaire à l'égard de coutumes et de statuts urbains très incomplets, ratio scripta, en face d'usages volontiers

72 Sur Dig. Vet. I, 1, $9 \mathrm{n}^{\circ} 1$.

73 Dès 1442 la Kammergericht royale appliquait la procédure romano-canonique.

74 Sic, T r u s e n, op. cit., Acta iuridica, XVII (1970) 137-139.

75 Par exemple l',Erneuerte Frankfurter Reformation” de 1578, oeuvre de Johann Fichard, ancien élève de Padoue et syndic de Francfort. 
tenus pour ,,irrationnels", le droit romain était ainsi devenu ius commune de l'Empire.

Dans les pays voisins de l'Allemagne, et dont certains faisaient partie de l'Empire germanique, le pénétration du droit romain se fit de façon plus ou moins accusée et pour chaque pays elle présente des caractères orginaux.

La B o hême avait subi l'influence du droit romano-byzantin au milieu du IXe siècle. Cyrille avait utilisé l'égloge byzantin pour sa loi judiciaire et Méthode fit traduire en langue slave le Nomocanon byzantin. Mais cette première infiltration romaine, venue par l'Orient, ne survécu pas au royaume de Grande Moravie.

$\mathrm{Au}$ XIII s. des contacts avec l'Italie marquent le début d'une action plus suivie. Des étudiants de Bohême fréquentent les Universités italiennes et des professeurs italiens viennent en Bohême. D'autre part, par l'intermédiaire du droit canonique, des solutions romaines sont connues et appliquées. Les bibliothèques d'Olomouc ou de Prague conservent des livres de droit romain. Mais on ne saurait parler d'une ,réception" du droit romain au XIII ${ }^{e}$ siècle.

Au XIVe la fondation de l'Université de Prague (1348), où une faculté de droit prolonge et développe le studium qui déjà auparavant enseignait le droit canonique, aurait pu favoriser la diffusion du droit romain. Mais la guerre hussite compromit l'essor de l'Université. Dans l'entourage des princes figurent cependant des juristes, qui fournissent le personnel des tribunaux, de l'administration et du gouvernement.

Les Constitutiones iuris metalli de Venceslas II (1301-1305), oeuvre d'un italien, codifient pour la première fois en Europe la procédure romano-canonique. Ce travail témoigne donc d'une tendance romanisante mais, n'ayant pas été officiellement publié, il resta un document privé, auquel d'ailleurs on se repporta souvent. La codification du droit local, faite sous Charles IV entre 1246 et 1355 (la Maiestat Carolina), fait au vocabulaire romain des emprunts formels, mais sans adopter ses solutions de fond. Le travail ne fut d'ailleurs pas non plus officiellement publié. Ces réticences et ces résistances à l'égard de toute codification, qui aurait fait une place aux solutions romaines, venaient surtout de la noblesse, inquiète pour ses privilèges. Le droit urbain de son côté se montrait rebelle aux influences romaines.

Les transformations politiques et intellectuelles du XVI ${ }^{e}$ s. furent au contraire favorables au droit romain. Le mouvement humaniste augmente son crédit. La dynastie des Habsbourg, qui règne en Bohême depuis 1526, crée des institutions qui le mettront en oeuvre. Le tribunal d'appel, instauré en 1548, compte, parmi ses douze membres, quatre docteurs en droit. Par leur connaissances ces derniers dominent leurs 
collègues et imposent le droit romain à la jurisprudence. Le droit municipal fait lui aussi une place au droit romain. Mais le rôle de ce dernier, même aux XVII et XVIII e siècles, reste limité. Un droit local, d'influence à la fois germanique et slave, lui opposa toujours une résistance efficace. C'est ainsi que les principes du droit successoral bohêmien se maintinrent très différents de ceux du droit romain ${ }^{76}$. Le droit naturel se révéla aussi un adversaire du droit romain, encore que, sous son nom et à côté de beaucoup de solutions germaniques, quelques notions romaines aient été acceptées.

Fautes d'études suffisantes, il est difficile de déterminer dans quelle mesure des notions romaines apparurent an $\mathrm{Autriche}$ dès le XIIIe siècle. Ici encore le droit canonique fut le premier véhicule de la pensée romaine. Comme en Allemagne et en Bohême, les $\mathrm{XV}^{\mathrm{e}}-\mathrm{XVI}^{\mathrm{e}} \mathrm{s}$. virent le progrès de la pénétration du droit romain en Autriche. Et l'on retrouve l'influence générale du mouvement humaniste, le rôle de l'enseignement du droit romain à l'Université de Vienne (créée en 1365), l'utilisation de ses élèves, devenus juges ou fonctionnaires d'une monarchie qui jette les bases d'un état moderne.

Mais le droit romain trouve dans les villes plus de réticences qu'en Allemagne et, dans les campagnes, seigneurs et paysans, pour des raisons d'ailleurs différentes, ne lui sont pas favorables. Son prestige ne sera guère servi au XVIII ${ }^{\text {e }}$ siècle par l'enseignement viennois qui manque de maître de renom ${ }^{77}$. Mais le droit romain marqua la codification de l'Allgemeine bürgerliche Gesetzbuch de $1811^{78}$.

En $\mathrm{H}$ ong $\mathrm{r}$ ie la connaissance du droit romain fut d'abord assurée par les clercs et le droit canonique. Elle fut favorisée par l'enseignement. Un studium generale existait à Veszprém dès la seconde moitié du XIII' s. et l'Université de Pècs fut fondée en 1367. D'autres le seront par la suite. Une codification du droit hongrois confiée par le roi à Etienne Werböezy aboutit à la rédaction d'un Opus Tripartitum (1514) qui, bien qu'il n'ait jamais été promulgué, fut largement utilisé par les Tribunaux. La marque romaine y est très sensible. La création d'une juridiction d'appel pour les tribunaux urbains en 1548 favorisa aussi une certaine diffusion du droit romain. Des formulaires du XVI ${ }^{\mathrm{e}} \mathrm{s}$. témoignent de l'importance du droit romain en Hongrie ${ }^{79}$. Toutefois on ne saurait parler pour la Hongrie d'une „réception”, comparable à celle qui se produisit en Allemagne et cela pour des raisons techniques et politiques.

${ }^{i 6}$ S. von B olla, Hergang der Rezeption in den bömischen Ländern, St. Koschaker, I, 383-389.

77 A. Steinwenter, Der Einfluss des römisches Rechts auf die Kodifikation des bürgerlichen Rechts in Österreich, St. Koschaker, I, 407-413.

is Ibid. 415-425.

$79 \mathrm{G}$. Bonis, Un libro di testo ungerese di diritto romano del cinquecento, Studi... Volterra, VI, 1969, 343-366. 
Le droit hongrois, dès le $\mathrm{XVI}^{\mathrm{e}}$ siècle, était moins divers que les droits locaux allemands et le besoin se faisait moins sentir d'un ius commune. D'autre part, et plus encore qu'en France, la défiance politique à l'égard de l'Empire incitait à quelques prudence envers le droit romain.

Malgrè une rapide diffusion du notariat ${ }^{80}$ et l'indéniable influence des officialités ecclésiastiques, les Cantons suisses, sans ignorer le droit romain, se montrèrent réservé à son égard. D'une façon générale le Valois et les Grisons furent moins réticents que les pays alémaniques, mais les cantons suisses restèrent avant tout pays de droit coutumier. Pas plus que la Hongrie, la Suisse ne connut une „réception” comparable à celle qui eut lieu en Allemagne. L'exemption de la juridiction du Reichskammergericht ne fut peut-être pas étrangère à cette prédominance coutumière ${ }^{81}$. Seul Bâle fit exception. L'accueil qu'y reçut le droit romain se rattache d'ailleurs au développement de l'humanisme juridique bâlois aussi bien qu'aux relations qui, dès le XIII ${ }^{\mathrm{e}} \mathrm{s}$., s'étaient nouées entre Bâle et l'Université de Bologne.

L'influence du droit romain en Pologne a fait l'objet de controverses entre les historiens de ce pays. Contestée par Kutrzeba, elle fut au contraire affirmée par R. Taubenchlag ${ }^{82}$. Certes Hostiensis rangeait la Pologne parmi les régions quae non utuntur legibus ${ }^{83}$ et, si l'on met à part les éléments romains que pouvait charier le droit canonique, on ne peut parler de pénétration romaine avant l'époque de la Renaissance. A l'Université de Cracovie, fondée en 1364, on n'enseigna pas le droit romain avant la fin du XVe siècle. Sans doute certains juristes polonais purent-ils s'initier à cette discipline avant cette époque, hors de leur pays. Mais c'était peu de chose.

$\mathrm{Au} \mathrm{XVI}^{\mathrm{e}}$ s. l'instauration d'une juridiction royale supérieure à Cracovie servit, comme les instances d'appel de l'Empire ou de Hongrie, la diffusion du droit romain. Les juridictions urbaines de leur côté se réfèrèrent volontiers au droit romain et plus encore à la Glose. En 1535, le juriste de Cracovie Nicolaus Jaskier publia une traduction latine des textes du droit germanique utilisée dans les villes polonaises: le „Saxenspiegel” (Speculum Saxonum) et le ius municipale de Magdebourg. Jaskier joignit à sa traduction la glose allemande de ces textes, qui utilisait largement la glose d'Accurse. L'ouvrage faciliait ainsi la diffusion en Pologne du droit romain. Publié avec l'approbation du rai Sigismond I Jagellon, il fut utilisé dans toute les villes polonaises qui sui-

80 Dès le XIIIe siècle dans le Valais; au XIVe à Bâle, Constance ou Zurich.

81 Sic, Stelling Mich a ud, L'Université de Bologne et la pénétration du droit romain et canonique en Suisse au XIII et XIVe siècle, Genève 1955.

${ }_{82}$ En dernier lieu dans sa publication postume: Einflüsse des römischen Rechts in Polen, IRMAE, 1962.

${ }^{83}$ Ad. c. $28, \mathrm{X}, \mathrm{V}, 33$. 
vaient le droit de Magdebourg. Divers traités de juristes polonais du $X V^{e}$ témoignent également de cette connaissance du droit romain ${ }^{84}$.

Mais les tribunaux des nobles, sauf en cas de silence du droit, se refusèrent à utiliser le droit romain ${ }^{85}$. A cette opposition de la noblesse, qui considèrait que le droit romain était dangereux pour ses privilèges, s'ajouta le souci politique de ne pas sembler reconnaître, par l'acceptation $d u$ droit romain, une suprématie de l'Empire ${ }^{86}$. Aussi le droit romain n'a-t-il jamais vraiment pénétré le droit coutumier polonais.

De ce tableau sommaire et souvent incomplet se dégagent néanmoins quelques constations.

1. Pas plus que dans l'Empire romain ce ne sont des raisons politiques qui ont assuré la diffusion du droit romain dans l'Europe entre le $\mathrm{XIII}^{\mathrm{e}}$ et le $\mathrm{XVI}$ e siècle. Rome ne pouvait pas alors imposer son droit par la force ou même par une contrainte indirecte. Et la théorie politique de la continuité de l'Empire ne constitua pas un argument pour l'imposer en Allemagne. Si l'argument politique joua quelque rôle ce fut pour s'opposer à une réception officielle du droit romain dans des pays qui comme la France, la Hongrie ou la Pologne, ne voulaient pas donner prise à une supériorité de l'Empire ${ }^{87}$.

2. Dans certains cas, et peut-être dans le Midi languedocien ou provençal, une première pénétration romaine fut servie par des relations commerciales avec l'Italie.

3. Mais, d'une façon beaucoup plus générale, c'est par la formation universitaire que le droit romain fut connu et apprécié. Sa supériorité technique lui assura une rapide diffusion, en attendant qu'on lui reconnut les mérites d'une raison écrite.

4. Toutefois, l'école n'est qu'un lieu d'étude qui tente de former des hommes instruits, en l'espèce de bons juristes. La diffusion du droit romain exigeait la mise en pratique de cette science. Ce fut à un niveau le plus modeste, mais dans la réalité quotidienne, l'oeuvre des praticiens, des notaires, des rédacteurs d'actes. Ce furent eux aussi d'ailleurs qui, devant les résistances populaires, imaginèrent les clauses de renonciation par lesquelles ils écartaient certaines solutions romaines.

${ }_{84}$ L. Pa uli, Römisches Recht in der Literatur des Stadtrechtes in Polen in der Renaissanceepoche, Acta iuridica et politica, XVII (1970) 69-77.

$85 \mathrm{~K} . \mathrm{B} \mathrm{uk}$ ow s k a, Das römische Recht in den Gerichtspraxis des XVI-XVIII Jahrhunderts in Polen, Acta iuridica et politica, XVII (1970) 19-20.

86 A. Vet u la $\mathrm{n} i$, Les entraves à la pénétration du droit romain dans le droit polonais médiéval, Miscellanea... Bidagor, I. Roma 1972, 62-65.

si R. A u benas propose ,une hypothèse" différente, lorsqu'il voit dans la renaissance et la diffusion du droit romain à partir du XIIe s. une des manifestations de "la grande entreprise impériale" de restauration de l'unité du "monde" (De quelques problèmes concernant la renaissance du droit romain au Moyen-Age, Rec. de Mém. et Trav... des anciens pays de droit écrit, VI (1967) 51—53). 
5. Mais la diffusion des solutions romaines, de la technique procédurale, des principes d'administration, voire de gouvernement fut l'oeuvre des officiers royaux, des juges, des administrateurs. L'apparition de ce personnel spécialisé est liée, dans toute l'Europe, à la formation de l'état moderne. Et celui-ci doit beaucoup à l'apport romain. Ainsi la réception et la diffusion du droit romain, produit de la renaissance universitaire du XIII au XV $\mathrm{XV}^{\mathrm{e}}$ s, est intimement liée aux grandes mutations qui substituèrent l'état aux seigneuries médiévales ${ }^{88}$.

\section{III - LE CODE CIVIL DANS L'EUROPE DU XIXème SIECLE}

C'est dans un tout autre monde politique et social que se fit, surtout dans la première moitié du XIX ${ }^{\mathrm{e}}$ s., la diffusion du code civil français en Europe ${ }^{89}$.

On doit à cet égard distinguer trois situations très différentes: l'application du code de 1804 dans des territoires annexés à l'Empire français, se réception avant 1815 dans des pays théoriquement indépendants mais en fait dociles aux désirs impériaux, son influence après 1815. Il est évident que dans ces trois cas les raisons qui sont à l'origine de la diffusion du code civil ne sont pas identiques.

1 - La réception du code ratione imperii dans les pays annexés. A la suite des conquêtes de la Révolution et du Consulat, la France de 1804, après les traités de Lunéville (9 Février 1801) et d'Amiens (27 Mars 1802) comptait 108 départaments. La Belgique ${ }^{90}$, la rive gauche du Rhin, le Jura bernois et Genève, le Piémont de Turin jusqu'à Parme ${ }^{91}$ sont parties intégrantes du territoire français. Le code de 1804 y entre donc de plein droit en vigueur ${ }^{92}$.

Il devint de la même façon applicable dans les territoires annexés par la suite et qui entrèrent dans le ,grand empire français". Celui-ci atteint son apogée, après la paix de Vienne (14 Octobre 1809) et les annexions de 1810, avec 130 départements. Aux annexions antérieures sont

88 Les réticences nobiliaires ou celles du monde rural confirment par a contrario cette étroite connexion.

${ }_{89}$ Voir à la fin de cette étude une orientation bibliographique sur ce sujet.

90 Incoropée au territoire de la République par Décret de la Convention du 9 Vendémiaire an IV.

${ }_{91}$ Ce dernier annexé le 11 septembre 1802.

92 C'est ainsi que le code civil est publié en Piémont le 20 mars 1804. Pour la Belgique, un arrêté du Directoire du 16 Frimaire an V y avait déclaré applicable de plein droit toute loi de la République publiée au Bulletin des Lois. De même sur la rive gauche du Rhin, occupée par les troupes françaises dès 1794 et rattachée par le Traité de Lunéville, les lois françaises et donc le code civil étaient applicables. L'introduction du droit français s'était faite sans grande difficulté en Rhénanie où le vieil ,Rechtsordnung” était très dépassé. Il n'y eut pas de conflit entre deux ordres juridiques, mais substitution d'une législation moderne à un droit vieilli. Ce n'est qu'en 1814 que le conflit apparaîtra entre le code civil et le Landrecht prussien de 1794 (cf. infra). 
venues s'ajouter celles de la Toscane et de la plus grande partie des Etats de l'Eglise, des provinces illyriennes, des Pays-Bas et d'une partie de l'Allemagne du Nord jusqu'à Lübeck. La promulgation du code suivit en général de peu les rattachements politiques ${ }^{93}$.

Dans le lointain Océan indien, l'île de France (Maurice), l'île de la Réunion et les Seychelles, possessions françaises, furent comme telles, soumises au code civil.

2 - Soumision politique et prestige scientifique. $\mathrm{Si}$ dans ces territoires l'introduction du code relevait de l'annexion, elle s'explique par des pressions plus subtiles, mais non moins efficaces, pour d'autres régions.

Il s'agit alors d'états en principe souverains, mais en fait dépendant de la volonté impériale. Celle-ci se manifesta, en matière législative, par l'obligation d'accepter le code civil.

Il est introduit dans le Royaume d'Italie (créé en Mars 1805 et dont l'Empereur est le souverain) en 1806 et dans le Royaume de Naples en $1812^{94}$. Le code est également adopté par plusieurs états de la Confédération du Rhin (1806): Royaume de Westphalie (Constitution du 15 Novembre 1807 art. 45, avec entrée en vigeur le $1^{\mathrm{er}}$ Janvier 1808); Principauté d'Arenberg ( $1^{\mathrm{er}}$ Janvier 1808); Grand Duchés de Berg (1 ${ }^{\mathrm{er}}$ Janvier

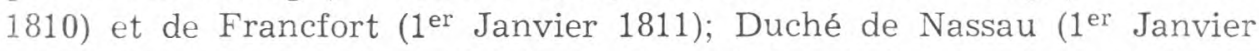
1812). Dans le Grand Duché de Bade, qui faisait lui aussi partie de la confédération du Rhin, l'introduction du code civil fut prescrite par $\mathrm{Na}-$ poléon à la fin de 1807. Mais le Grand Duc voulut y apporter certains aménagements pour tenir compte des traditions locales. Une commission fut chargée de cette adaptation. Elle acheva son travail en 1809 et le $1^{\text {er }}$ Janvier 1810 entrait en vigueur le „Code Napoléon mit Zusätzen und Handelsgesetzen als Landrecht für das Grossgerzogtum Baden". Ce code restera en vigueur jusqu'à l'introduction du BGB, le $1^{\text {er }}$ Janvier 1900.

Des projets d'introduction du code civil dans d'autres pays de la Con-

93 En 1805 à Gènes (quelques mois après l'annexion à la France); la même année à Parme; cn 1806 à Plaisance et à Lucques; en 1809 en Toscane; en 1812 dans les états pontificaux (annexés le 17 février 1809). Le code civil est introduit dans les départements hanséatiques par un sénatus-consulte des 10-13 décembre 1810. Dans les Pays-Bas la situation politique, et à sa suite la situation juridique, firent l'objet de plusieurs modifications. La République batave, créée en 1795, devint en 1806 le royaume de Hollande confié à Louis Bonaparte. Mais en 1810 Napoléon reprend le royaume à son frère et le place sous son gouvernement. Sur instruction de l'Empereur (Lettre à Louis du 31 octobre 1807, Corresp., t. XVI, 155), le roi de Hollande par Décret du 24 février 1809 avait introduit dans son royaume à la date du 1er mai 1809 le code civil, sous la forme d'un ,code Napoléon arrangé pour le Royaume de Hollande". Mais, aprés la cession des provinces méridionales à la France (traité du 16 mars 1810), un Décret impérial du 8 novembre 1810 introduisit les cinq codes français à partir di 1er janvier 1811, puis un Décret du 6 janvier 1811 les rendit applicables dans toute la Hollande à dater du 1er mars.

${ }_{94}$ Mais il ne fut introduit ni en Sicile, ni en Sardaigne. 
fédération, Bavière, Hesse, Darmstadt, Wurzburg furent envisagés. Mais la défaite de Napoléon à Leipzig (16-18 octobre 1813) les rendit caducs.

A côté de cette pénétration officielle par la législation, il faut faire une place au mouvement doctrinal qui, à l'époque de l'apogée de l'Empire, porta grand intérêt au code civil et parfois même le proposa comme droit commun européen ${ }^{95}$. Johann Nikolaus Fredrich Brauer (1754-1843), rédacteur du "Landrecht” de Bade, publia en six volumes des Erläuterungen über den Code Napoléon und die Grossherzoglich-Badische bürgerliche Gesetzgebung (1809-1812). L'ouvrage le plus célèbre en ce domaine est sans conteste le Handbuch des französchichen Civilrecht de Zachariae von Lingenthal (1769-1843) ${ }^{96}$. Professeur de droit français aux Université de Fribourg puis de Heidelberg, Zachariae von Lingenthal contribua au maintien du code civil dans le Grand Duché de Bade. Par un curieux retour, c'est en s'inspirant de la méthode et du plan de Zachariae, dont ils pensaient tout d'abord se borner à traduire l'oeuvre, qu'Aubry et Rau entreprirent la publication de leur Cours de droit civil français, sans doute le plus important Traité de droit civil paru en France au XIX ${ }^{\text {ème }}$ siècle.

L'exemple de Zachariae montre donc que ce n'était pas seulement le prestige de l'Empereur ou le désir de lui plaire qui contribuèrent à la diffusion du code civil. Certes ces considérations ne doivent pas être minimisées. Et le sort qui parfois frappa le code après la chute de l'Empire en cst la preuve. Mais, comme on le verra plus loin, le code civil fut loin de se replier sur la seule France après 1815. Ses qualités scientifiques et la consécration qu'il donnait aux aspirations de l'époque, qu'il s'agisse de l'égalité civique, de la propriété, du droit successoral garantirent son succès.

L'application du code Napoléon fut prescrite dans le Grand Duché de Varsovie par un Décret de Frédéric Auguste, roi de Saxe et duc de Varsovie, du 27 Janvier 1808. Comme dans certaines régions de l'Allemagne, le code resta en vigueur après 1813 dans le Royaume de Pologne (18151830 ) et même, au moins partiellement, pendant tout le $\mathrm{XIX}^{\mathrm{e}}$ siècle.

3 - Le rayonnement scientifique du code civil a près 1815 . Après s'être imposé ratione imperii, le code civil jouira d'un indéniable prestige en Europe imperio rationis.

Ce n'est pas cependant qu'il n'ait connu des adversaires. En Allemagne, à l'enthousiasme excessif de Reitemeier répondaient dès 1814 les propos d'un homme d'état du Hanovre, August Wilhelm Rehberg (1757-

95 J. L. R e itemeie r, Das Napoléonsrecht als allemeines Recht in Europa, inbesondere in Deutschland betrachtet, 'Francfort sur l'Oder 1809.

${ }_{96}$ Publié en 1808, l'ouvrage connut de multiples éditions même aprés la mort de son auteur. 
1836) Über den Code Napoleon und dessen Einführung in Deutschland. Plus illustre est demeurée l'hostilité de Savigny. Sans doute, dans sa controverse avec Thibault, c'était l'idée même de codification qu'il condamnait au nom de la spontanéité de la création juridique ${ }^{97}$. Mais il en avait aussi au code civil, à son contenu et à l'impérialisme politique dont il était comme le symbole. Aussi en 1818 voulait-il que les pays rhénans l'abandonnent „Dieses kann wegen seines Inhalts und aus politischen Gründen nicht fortbestehen”. La Prusse entreprit effectivement de substituer son droit au code civil dans les pays rhénans passés sous son autorité. Mais ici, certaines distinctions s'imposent ${ }^{98}$.

Une partie du pays de la province prusienne du Rhin (les anciens pays prussiens, Duisbourg, Essen et quelques autres territoires) retrouvèrent dès 1814 le droit prussien. Le code civil ne resta applicable que sur la rive gauche et, pour la rive droite, dans une partie de l'ancien Grand Duché de Berg. En 1816 une commission était nommée par le roi de Prusse pour étudier les modalités d'introduction de l',,Allgemeine Landrecht für die Preussischen Staaten" de 1794. Elle la subordonna à une réforme préalable du droit prussien. En fait c'était un ajournement sine die et le code civil persista jusju'au BGB de 1900. La bourgeoisie libérale restait favorable au code français qui répondait mieux à ses conceptions. Dans les années quarante des travaux scientifiques fortifièrent son audience en mettant en évidence des traits tenus pour „germaniques" 99, cependant qu'un mouvement en faveur de l'unification et de la codification du droit en Allemagne s'esquissait 100. Cette unification apparaissait comme le seul moyen d'éliminer le code civil. Son plus puissant adversaire, Savigny, „Gesetzgebung Minister” en Prusse depuis 1842, était éliminé par la Révolution de 1848. Sans doute la codification allemande devait attendre un demi-siècle. Mais loin de disparaître, l'influence du droit français, en particulier en certain domaine du droit de famille, se fit sentir dans des lois de l'Empire allemand entre 1870 et la promulgation du code de 1900101 .

En I t a li e, le code civil français, qui avait progressivement gagné toute la pénisule, ne put maintenir ses positions après 1814. Le pape et les princes l'abrogèrent en reprenant possesion de leurs états et en 1816 le royaume lombardo-vénitien adoptait le code civil autrichien.

97 Dans le libelle fameux ,Vom Beruf unseres Zeit für Gesetzgebung uns Rechtswissenschaft", 1814.

${ }_{98}$ H. C o n r a d, Preussen und das französische Recht in den Rheinlanden dans „Recht und Rechtspflege in den Rheinlanden”, Köln 1970, 78-108.

${ }_{99} \mathrm{H}$. Z o e pfl (1807-1877), Über der germanische Elemente des Code Napoléon (1841).

100 Dès 1815, le rhénan Joseph von Görres (1776-1848) écrivait dans le Rheinisches Merkur (du 7 Avril): „Ein Reich, ein Recht”.

101 H. C o n r a d, op. cit., 96-98. 
Mais quatre codification locales vont bientot faire de larges emprunts au code Napoléon et le réintroduisent sous un vêtement „national”. Il en va ainsi du code du Royaume des Deux Sicile de 1819, de celui de Parme et de Plaisance de 1820, du "Codice Alberto", de Charles Albert pour la Sardaigne et le Piémont (1837) et du code de Modène de 1851. Le code piémontais inspirera largement le code civil italien de 1865, qui se trouva ainsi profondément marqué par l'influence française 102.

Celle-ci persista également en Suisse. L'acte de réunion du Jura bernois au canton de Berne en 1815 posait le principe de l'abrogation des lois françaises (art. 14 et 15). Mais ces dispositions restèrent lettre morte et le droit français persista, A Genève il resta également à la base de la législation, encore que diverses lois s'en soient écartées au cours du XIX $^{\mathrm{e}}$ siècle. Quant aux codes cantonaux, tels ceux du Vaud du $1^{\text {er }}$ Juillet 1821 ou de Neufchâtel de 1853/54 et, dans une moindre mesure, ceux du Fribourg (1834-1850), du Valais (1855) ou du Tessin (1837), ils s'inspirèrent largement du modèle napoléonien.

Par la volonté des Alliés, le traité de Paris du 30 Mai 1814 et le traité des huit articles de Londres du 20 Juin 1814 réunissaient à nouveau B e 1gique et Pays-Bas sous l'autorité d'un même souverain, Guillaume I d'Orange-Nassau. L'art. 163 de la loi fondamentale des Pays-Bas de 1815 prévoyait ,pour tout le Royaume un même code civil, un même code pénal, un même code de commerce, un même code d'organisation judiciaire et de procédure civile". C'était déjà, à l'exception du code d'instruction criminelle de 1811, la reprise formelle de la liste des codes napoléoniens!

Dès 1813 une commission avait été chargée de la révision du code civil, applicable en Hollande deouis le $1^{\mathrm{er}}$ Janvier $1811^{103}$. La commission devait s'inspirer dans cette révision de l'esprit qui avait présidé à l'élaboration du code de 1809 pour le Royaume de Hollande. Il s'agissait donc, en réaction contre l'imposition globale du Code Napoléon, de tenir compte dans le code nouveau des traditions locales. Un avant-projet, préparé par Kemper, fut soumis au roi le 5 Mars 1816. Mais les députés des provinces du Sud (actuelle Belgique), qui restaient fidèles au code français, firent échouer le projet devant la Chambre en 1821. Il fallut reprendre les travaux, non sans de grande difficultés, dues surtout aux réticences belges. On parvint cependant à la mise sur pieds d'un nouveau code, promulgé par une loi du 16 Mars 1829. Son entrée en vigueur avait été reportée au $1^{\mathrm{er}}$ Février 1831. La Révolution belge de 1830, la sécession des provinces méridionales formant le Royaume de Belgi-

102 Celle-ci reste sensible dans le code civil italien de 1942.

103 Cf. supra. 
que empéchèrent la mise en application d'un code fait pour un royaume, désormais scindé en deux.

Cependant le texte de 1829 fut repris dans le Royaume de Hollande. Revisé en 1832 et 1833 il aboutit au code civil publié le 10 Avril 1838 pour entrer en vigueur le $1^{\mathrm{er}}$ octobre suivant. Riche de 2030 art. (2281 dans le Code Napoléon), le code reprenait la quasi-totalité des dispositions du code français, sauf quelques dispositions concernant les incapables, celle qui autorisait le testament olographe et quelques textes mineurs. Cependant la Hollande érigeait la communauté universelle en régime de droit commun pour régler les rapports patrimoniaux entre époux. La place faite dans le code aux traditions locales était faible. Solutions françaises, romaines, canoniques ou germaniques représentaient les quatre-cinquième du code néerlandais.

En Belgique, l'un des premiers actes du gouvernement provisoire fut de s'opposer à la mise en application le $1^{\text {er }}$ février 1831, du code voté en 1829 (arrêté du 14 Janvier 1831). Le code civil français resta en vigueur et ceci par la libre volonté du gouvernement belge. Sans doute l'art. 149 de la constitution belge de 1831 prévoyait sa révision. Mais celle-ci n'eut pas lieu.

D'autres codifications, plus tardives, empruntèrent dans une mesure plus ou moins étendue au code de 1804. Le code civil roumain de 1864 n'était qu'une traduction légêrement modifiée du code civil français ${ }^{104}$. En Espagne, le travail de codification commencé dès 1821 s'inspira largement de l'exemple français. Un nouveau projet préparé en 1851 aboutit au code de 1889 où la marque du code de 1804 est sensible. Le code civil portugais de 1867 se montre dans son plan très original et rompt avec le modèle français. Mais il s'en inspirait largement dans le détail de ses dispositions.

L e Q uébec qui, comme colonie française avait vécu au XVIII $\mathrm{s}$. sous l'empire de la Coutume de Paris et d'ordonnances royales, garda sa législation après sa cession à l'Angleterre par le Traité de Paris de 1763. Le roi Georges III tenta cependant d'y introduire le droit anglais, mais dès 1774 ce projet fut abandonné et il fut entendu que l'on maintiendrait le droit ancien.

En 1857 fut entrepris un travail de codification qui aboutit au code de 1866. Celui-ci portait largement la marque du code civil, mais restait plus encore fidèle au droit coutumier français.

Ancienne colonie de la Couronne de France, récupérée en 1800 mais

104 Le code civil serbe de 1844 empruntait également au code français soit directement, soit par l'adoption de solution du code autrichien de 1811 qui avait lui-même repris certaines dispositions du code Napoléon (B. T. B lag a jevic, L'influence du code civil sur l'élaboration du code civil serbe, Rev. intern. de droit comparé, 1954, 733-743). 
cédée aux Etats Unis dès 1803 par le Traité de Paris, la L o u is i a n e adopta curieusement en 1808 non le code de 1804, mais le projet de code civil de l'An VIII. Un nouveau code promulgé en 1825 utilisait largement le code civil dans son édition de 1808 tout en empruntant aussi à Pothiers, à Toullier et à la jurisprudence française. Plus développé que le code civil, le code de la Louisiane comptait 3522 articles (au lieu des 2281 du c. civ.) ${ }^{\mathbf{1 0 5}}$.

En 1825 la République de $\mathrm{H}$ a iti promulga un code qui s'appliqua dans toute l'île. Ce code, qui entra en vigueur en 1826, était directement inspiré du code français. Ayant recouvré son indépendance en 1844, Saint Dominique adopta l'année suivante le code civil français lui-même dans sa version de l'époque de la Restauration. Il s'agissait alors de l'adoption intégrale d'un code étranger en lui conservant sa langue originale. Après l'annexion de Saint Dominique par l'Espagne (1861) on conserva le code français, mais il fut publié en espagnol (1862). Mais lorsque Saint Dominique eut repris son indépendance (1865) ce fut à nouveau le code dans sa version française et tel qu'il était applicable en France qui fut appliqué (1874). Traduit en espagnol en 1884, il fut conservé sous cette forme dans la république dominicaine.

La diversité de ces exemples, qui ne prétendent nullement aboutir à un tableau complet ${ }^{106}$, suffit à faire apparaître la complexité des phénomènes de reception à l'époque contemporaine dans le cadre d'états nationaux, fortement administrés et ayant atteint un haut degré de culture.

Liée parfois à l'annexion politique, elle lui survit souvent et ne le requiert toujours. La proximité géographique, une certaine communauté culturelle, l'identité de langue la favorisent, sans toujours la provoquer. La réception peut d'ailleurs s'opérer au loin, dans une société assez profondément différente. Enfin elle est plus ou moins massive, parfois presque totale lorsqu'il s'agit de l'adoption du code sans profondes modifications, dans d'autres cas plus nuancée, le code ,reçu” étant partiellement modifié pour tenir compte de traditions locales.

Si de ces exemples du siècle dernier on passe à une appréciation plus générale du phénomène, les trois périodes que nous avons retenues et les conditions très diverses qu'elles nous ont permis de relever suggèrent les observations suivantes.

10.5 J. D a in o n, Le droit civil de la Louisiane, Rev. intern. de droit comparé, 1954, 19-38.

196. Nous n’avons pas envisagé les pays d'Amérique latine, ni l'influence du code civil en Egypte ou au Japon. 
Le „réception” (et nous prenons ce terme dans son acception la plus large, recouvrant par conséquent des types de ,pénétration” très différents) n'est pas dans le domaine juridique l'effet de la conquête, de la violence ni de la contrainte.

Sans doute l'avons-nous vu parfois suivre la conquête militaire ou résulter de la volonté d'un maître tout-puissant. Il s'agit là de cas exceptionnels. Si la conquête a servi le code civil, ce n'est pas à elle qu'il dut son plus grand rayonnement ${ }^{107}$. Si Rome a conquis le monde, elle ne lui a pas imposé son droit. Et le prestige politique de l'impereur, successeur des empereurs de Rome, n'explique pas - même en Allemagne le succès médiéval du droit romain.

Le rayonnement d'un droit tient à d'autres causes et qui sont d'un autre ordre. D'abord, sans doute, à ses qualités techniques, à sa précision et sa simplicité (ce qui ne veut pas toujours dire sa facilité). Cette supériorité technique a fait le succès du droit romain dans l'Empire. Elle explique, à partir du XIII ${ }^{\mathrm{e}}$ s., la place qui lui fut faire à côté des coutumes.

Le succès sera d'autant plus facile que la lutte sera plus inégale, soit que les usages locaux demeurent sommaires, soit qu'ils négligent de réglementer d'amples secteurs des relations sociales (une bonne part du droit des contrats et des obligations dans les coutumes de l'Europe médiévale).

Ce qui fait apparaître une autre raison de ces réceptions, l'ampleur des transformations d'une société, si vastes et si profondes que les usages ancestraux ne suffisent plus. Témoins d'un passé révolu ils n'offrent plus les solutions qu'exige un monde nouveau. Ce fut l'une des raisons du succès du droit romain au Moyen-Age. C'est, d'une façon différente, l'une des causes essentielles de la diffusion du code civil au XIX ${ }^{\mathrm{e}} \mathrm{s}$. Essai de voie moyenne au landemain de la crise révolutionnaire, il traduisait les aspirations de la bourgeoisie victorieuse. Laïcisation du mariage, autorité du mari et du père, garantie de la propriété individuelle, égalité successorale, triomphe de l'autonomie de la volonté dans le domaine contractuel, simplicité des actes et rejet du formalisme, autant de traits qui répondaient à l'idéal de la bourgeoisie qui, plus ou moins vite, mais partout en Europe, accède au pouvoir.

A quoi l'on pourrait ajouter que la diffusion que connut alors la langue française, le prestige d'une culture, les qualités de forme du code, la simplicité de son style contribuèrent d'une façon non négligeable à son succès ${ }^{108}$.

107 Il fut appliqué à Haiti et à Saint Dominique bien que la souveraineté politique de la France y ait été fort précaire sous l'Empire.

$108 \mathrm{Cf}$. à cet égard les observations de F. H. Law s o n, Réflexions d'un juriste anglais sur le cent-cinquantenaire du code civil, Rev. intern. de droit comparé, 1954, 665-677. 
Si l'adoption d'un droit étranger, en totalité ou pour partie, est facilité et parfois provoquée par la conformité de ce droit aux aspirations d'une société, elle risque au contraire de susciter de graves crises ou de sérieux mécomptes lorsque le droit ,importé" heurte profondément de vieilles traditions locales. Présenté comme un signe de progrès, il peut n'être que générateur de troubles. Les exemples ne manquent pas dans un passé récent de semblables échecs.

De même ne saurait-on méconnaître l'importance des donnés linguistiques. Rédigé dans une langue étrangère, le droit étranger risque de se heurter à certaines résistances. On a vu, par exemple, que les actes médiévaux du Rouergue rédigés en français avaient été plus longtemps rebelles à l'infuence romaine que ceux rédigés par des scribes qui connaissaient un peu de latin. Si la Belgique se montra plus favorable que la Hollande à la conservation du code civil, c'est sans doute qu'elle se sentait culturellement plus proche de la France, et peut-être aussi parce que la langue française y était plus répandue. Le Québec, qui garda le droit français, usait aussi de la langue française.

Mais d'autres exemples, et beaucoup plus nombreux, prouvent que la différence de langue d'empêche pas l'adoption du droit. Et c'est ici qu'une distinction s'impose.

Lorsque la réception est l'oeuvre des praticiens, des rédacteurs d'actes qui, de leur propre gré, adoptent des solutions étrangères, il faut qu'ils les connaissent, donc qu'ils connaissent la langue dans laquelle elles ont été formulées. Le peu de connaissance du latin des scribes provinciaux de l'Empire romain, leur médiocre culture juridique transparaissent dans les fautes des actes, fautes de forme mais bien souvent aussi erreurs juridiques.

Mais lorsque la réception est le fait de juriste savants, lorsqu'elle est préparée par l'enseignement universitaire, la différence linguistique n'est plus un obstacle. Ou plutôt, c'est une difficulté aisément vaincue. Les clercs médiévaux savaient le latin, de même que les juristes cultivés

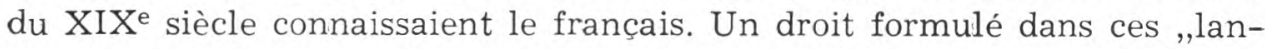
gues de culture" était accessible aux esprits cultivés. A eux, s'ils l'estimaient utile, de le traduire dans leur langue propre et ainsi de le rendre accessible à tous.

Car la réception n'est pas automatique. Elle peut résulter de l'ordre d'un législateur. Solution dont l'époque contemporaine est seule à donner des exemples, parce que notre temps est celui du triomphe de l'état et de la primauté de la loi.

Mais cette loi n'est elle-même que le fait d'hommes et c'est en dernière analyse la volonté humaine qui fait la réception. Volonté qui suppose la connaissance du droit que l'on veut diffuser. 
On en arrive ainsi au processus suivant: c'est par l'enseignement juridique que la transmission d'un droit à une société étrangère est rendue possible: enseignement savant des Universités ou petites écoles locales, peut-être formation orale très modeste, donnée par un praticien à quelques élèves. La connaissance acquise doit être diffusée, sans qu'elle soit toujours imposée par la loi. La diffusion est le fait de ces anciens élèves, pénétrés du droit dont ils peuvent mesurer la supériorité et qui sont devenus juges, officiers, notaires ou écrivains. Le droit nouveau est ainsi diffusé par les traités doctrinaux, les formulaires, les sentences judiciaires, les actes de la pratique, souvent plus que par la loi.

En présence d'une telle diversité des causes, des modalités et des agents, on s'expique l'embarras que nous dénoncions au début de cette étude et toute l'anbiguité de la ,réception".

\section{ORIENTATION BIBLIOGRAPHIQUE}

\section{I - PROBLĖMES GÉNÉRAUX}

René D a vi d, Traité élémentaire de droit civil comparé, Paris 1950.

Ernst Levy, The reception of highly developed legal systems by peoples of different cultures, Washington Law Review, XXV (1950) 233-245 = Gesammelte Schriften, I (1963) 210-223.

Ferid Ayiter, Das Rezeptionsproblem im Zeichen der kulturhistorischen Perspektive „Europa und das röm. Recht” und unter besonderer Berücksichtigung der Rezeption westeuropaischer Gesetzbücher in der modernen Turkei, Studi in memoria di P. Koschaker, II, Milano 1954, 133-156.

Henri Lévy-Bruhl, Note sur les contacts entre les systèmes juridiques, Symbolae Taubenschlag, I = Eos XLVIII (1956).

Le pluralisme juridique (recueil d'études comparatives, Institut de Sociologie, Bruxelles 1972).

II - LA „RECEPTION DU DROIT ROMAIN DANS L'OCCIDENT MÉdIÉVAL

Alle mag $\mathrm{ne}$

B elows, Die Ursachen der Rezeption des römischen Rechts in Deutschland, Hist. Bibl. Beiheft, X, 1927.

H. Coing, Die Rezeption des röm. Rechts in Francfurt am Main, 1939.

- Das Eindringen des röm. Rechts in das Recht des Hochmittelalters in Deutschland, Düsseldorf 1955 .

- La Pre-recione in Germania, Ann. di Storia del diritto, III-IV, 1959/60.

- Römisches Recht in Deutschland, IRMAE, V, 6, 1964.

H. K r a u s e, Kaiserrecht und Rezeption, Abhandl. der Heidelb. Ak. der Wissenschaft. Philol.-Hist. Kl. 1952 (et l'important c. r. de R. Feenstra, T. R. XXII (1954) 263-275). 
A. Katsuta, ,Was ist die Rezeption des röm. Rechts?" Eine Überlicht ihrer dynanischen Problematik, Hitotsubashi Journal of Law and Politics, IV (1965) 31-44.

- Friedrich Barbarossa und die sogenannte „Theoretische Rezeption des röm. Rechts", Hitotsubashi Journal of Law and politics, V (1967) 20-37.

J. M. Scholz, Der brandenburgische Landrechtsentwurf von 1594. Eine Studie zur Rechtsetzungslehre der Rezeptionzeit, Köln 1973.

R. Ganghoffer, Droit savant et droit pénal à l'époque de Charles Quint, Rech. et Doc. de la Société savante d'Alsace et des régions de l'Est, XVII (1973) $111-122$.

W. Trusen, Zur Rezeption des röm. Rechts in Deutschland, Acta juridica et politica, XVII (1970) 121-141.

Angleterre

John L. B a r to n, Roman Law in England, IRMAE 1971.

A utriche

A. Stein w e ter, Der Einfluss des röm. Rechts auf die Kodifikation des bürgerlichen Rechtes in Österreich, St. Koschaker, I, Milano 1954, 403-426.

Egon W e iss, Einige Bemerkungen zur Rezeption des röm. Rechts in den Österreichischen Alpenländern, St. Koschaker, I, 393-402.

H. B a 1t1, Einflusse des römischen Rechts in Österreich, IRMAE 1962.

Belgique et $\mathrm{Pays}-\mathrm{Bas}$

J. Gilis sen, Romeins Recht en inheems Gewoontrecht in de Zuidelijke Nederlanden (XII-XVI), Tydskrift vir Hedendaagse Romeins Hollandse Reg, Pretoria 1955, 97-139.

R. Feenstra, Zur Rezeption in den Niederlanden, St. Koschaker, I, 245-268.

- Keizerrecht en romeins Recht in Friesland, Mededeil der Vereeniging tot uitgeef der bronnen van het oud vaderlandsche recht, XI (1954) 177-252.

H e rmes dorf, Römisches Recht in den Niederländen, IRMAE, V, 5a, 1968.

Joris, Notes sur la pénétration du droit savant au pays de Liège (XII-XIV), T. R. XL (1972) 183-205.

L. Th. M a es, La réception du droit romain dans le droit pénal malinois, Mél. de Visscher, IV, 111-126.

R. van O a e n e e m, Le droit romain en Belgique, IRMAE 1966.

B o h ê m e

Sibylle Von Bolla, Hergang der Rezeption in den bömischen Ländern, St. Koschaker, I, 375-391.

$\mathrm{V}$ a n e č e $\mathrm{k}$, La penetrazione del diritto romano e canonico nel territorio dell'odierna Cecoslovacchia a partire della seconda metà del IX secolo fino alla prima metà del secolo XIV, Atti del Covegno intern. di Studi accursiani (Bologne 1963), Milano 1968, III, 1277-1291.

Ecosse

A. H. Campla 11, Diritto scozzese e diritto romano, Bartoldo da Sassoferrato I (1962) $77-87$.

P. S t e in, Roman Law in Scotland, IRMAE 1968. 
Es pagne

Anna M. B a r r e r o, El Derecho en los „Fuero” de Valencia de Jaime I, AHDE XLI (1971) $639-664$.

José M. F on t $\mathrm{Ru}$ iz, La reception del derecho romano en la peninsula iberia durante la edad media, Rec. Mém. et Trav... des pays de droit écrit, VI (1967) 85-104.

Jesus $\mathrm{L}$ a linde $\mathrm{A}$ ba dia, La reception espanola del s. c. Velleyano, AHDE XLI 1971) $335-371$.

France

R. A ubenas, Quelques réflexions sur le problème de la pénétration du droit romain dans le Midi de la France, Ann. du Midi, LXXVI (1964) 371-372.

J. Bréjon de Laveregnée, La pénétration du droit romain dans les pays de l'Ouest de la France, Rec. Mém. et Trav... des pays de droit écrit, VI (1967) $55-61$.

M. C a rli n, La pénétration du droit romain dans les actes de la pratique provençale (XI-XIIIe s.), Paris 1967.

G. Chevrier, Les étapes de la pénétration du droit romain dans le Comté de Bourgogne au XIIIe s., MSHDB XIX (1957) 37-43.

P. Du p a c, La pénétration du droit romain en Savoie, RHD 1965, 22-86.

J. G a u d e met, Observations générales sur l'influence du droit romain en France, Romanitas VI-VII (1965) 102-129.

A. Gouron, Diffusion des consulats méridionaux et expansion du droit romain aux XIIe et XIIIe s., Bibl. éc. Chartres CXXI (1963) 26-76.

- Commerce et diffusion du droit romain, Etudes à la mémoire de H. Cabrillac, Paris 1968, 204-218.

- Remarques sur les influence italiennes dans la pratique juridique du Midi de la France au XIIe s., „Atti del Convegno sui glossatori” 1971, Ist. Lomb., Acc. di Sc. e lettere 1973, $71-83$.

J. Ph. Lévy, La pénétration du droit savant dans les coutumiers angevins et bretons au Moyen-Age, T. R. XXV (1957) $1-53$.

- La pénétration du droit romain dans le vieux coustumier de Poitou, Mél. Petot, Paris 1958, 371-383.

P. O u r li a c, Troubadours et juristes, Cahiers de civilisation médiévale, VIII (1965) 159-177.

- Note sur les actes rouergats du XIIe siècle, Rec. de Mém. et Trav... des pays de droit écrit, VI (1967) 13-16.

- La société languedocienne du XIIIe s. et le droit romain, Cahiers re Fanjeaux 6 (1971) 199-216.

Jean $\mathrm{Hil}$ a i re, Pratique notariale et influence universitaire à Montpellier à la fin du Moyen-Age, Hommages à A. Dupont, Montpellier 1974, 167-178.

Hongrie

György B o nis, Enflüsse des römischen Rechts in Ungarn, IRMAE, V, 10 (1964).

- La pénétration du droit romain dans les pays slave et hongrois, Rec. Mém. et Trav... des pays de droit écrit, VI (1967) $77-83$.

- Un libro di testo ungherese di diritto romano del cinquecento, Studi... Volterra, VI (1969) 343-366.

I. Z a jtay, Sur le rôle du droit romain dans l'évolution du droit hongrois, St. Koschaker, II, 181-211. 
Pays baltes

H. Bla ese, Einflüsse des römischen Rechts in den baltischen Gebieten, IRMAE 1962.

Pays slaves du Sud

M. A n dre ev, Sur le problème de la réception du droit romain dans les pays des slaves du Sud, Acta juridica et politica, XVII (1970) 9-13.

Pologne

R. T a u be n $\mathrm{chl}$ a g, La storia della recezione del diritto romano in Polonia fino alla fine del secolo XVI, St. Koschaker, I, 225-242.

- Einflüsse des römischen Rechts in Polen, IRMAE 1962.

K. B ukowska, Das römische Recht in den Gerichtspraxis des XVI-XVIII Jahrhunderts in Polen, Acta juridica et politica, XVII (1970) 15-25.

- Quelques remarques sur l'application du droit romain dans les villes polonaises du XVI-XVIIe siècle à la lumière de la pratique du tribunal supérieur du Chateau de Cracovie, Studi Volterra, VI, 207-217.

L. P a u li, Römisches Recht in der Literatur des Stadtrechtes in Polen in der Renaissanceepoche, Acta juridica et politica, XVII (1970) 67-77.

St. Salmonowicz, Le droit romain en Pologne à l'époque de lumières, Studi Volterra, II (1969) 352-370.

A. Vetulani, La Pologne médiévale et le droit romain, Studi Volterra, I (1969) 289-307 et Acta juridica et politica, XVII (1970) 143-149.

- Les entraves à la pénétration du droit romain dans le droit polonais médiéval, Miscellanea Bidagor, I, Romo 1972, 53-68.

R. Chabanne, Les principales étapes de la pénétration du droit romano-canonique dans la Pologne médiévale, Mélanges Falletti, Paris 1971, 67-84.

$\mathrm{S} u$ è $\mathrm{d} e$

Rehfeldt, Berbhard, Rezeption in Schweden, ZSS Germ. Abt., LXXXII (1965) 316-326; LXXXIV 1967) 248-252.

Suisse

Beck, Romanistische Bemerkungen zu früheren Bernischen Rechtsquellen (bis zur 1. Hälfte des 14. Jhts.), Festschrift für H. Rennefart 1958, 215-242.

Otto Clavadetscher, L'influence du droit romain en Rhétie au XIII et au commencement du XIVe s., MSHDB XVIII (1956) 45-63.

H. R. H a g e m a n n, Basler Stadtrecht im Spätmittelalter, ZSS Germ. Abt., LXXVIII (1961) $140-297$.

G. K is ch, Bartolo e Rasilea, Bartolo da Sassoferrato, I, 1962, 349-368.

$\mathrm{G}$. Parts ch, Un aspect de la première apparition du droit romain en Valais et

à Genève au XIIe et au début du XIIIe s., MSHDB XIX (1957) 59-75.

$\mathrm{H}$. P e te r, Le droit romain dans la région zurichoise, MSHDB XVIII (1956) 65-69.

P. W a 11 is e r, Römischrechtliche Einflüsse im Gebiet des heutigen Kantons Solothurn von 1500, Basel 1965. 


\section{III - LA „RÉCEPTION” DU CODE CIVIL EN EUROPE AU XIXe SIECLE}

C. D. A s s e r, Le code civil dans les Pays-Bas, Livre du Centenaire du code civil, II, Paris 1904, 817-845.

B. T. Blagojevic, L'influence du code civil sur l'établissement du code civil serbe, Rev. intern. de droit comparé, 1954, 733-743.

G. B. Chironi, Le code civil et son influence en Italie, Livre du Centenaire..., $763-777$.

$\mathrm{H}$. Con r a d, Preussen und das französische Recht in den Rheinlanden, Recht und Rechtspflege in den Rheinlanden, 1969, 78-108

J. Da inow, Le droit civil de la Louisiane, Rev. intern. de droit comparé, 19-38.

C. G. Diss es c u, L'influence du code civil français en Roumanie, Livre du Centenaire..., 849-871.

Goraï, Influence du code civil français sur le Japon, Livre du Centenaire..., $781-790$.

$\mathrm{H}$ a n s s e n s, Le code civil en Belgique, Livre du Centenaire..., 679-722.

Is himoto, L'influence du code civil français sur le droit civil japonais, Rev. intern. de droit comparé, 744-752.

E. Meiller, Le code civil en Allemagne, Livre du Centenaire..., 627-638.

F. B. Mign a $1 \mathrm{t}$, Le code civil au Canada, Livre du Centenaire..., 723-731.

R. Pir e t, Le Code Napoléon en Belgique, Rev. intern. de droit comparé, 753-791.

R. W a rlomont, Les influences belge et française sur le Code civil néerlandais de 1838, RHD 1955, 412-437.

I. Z a j t a y, Les destinées du Code civil, Rev. intern, de droit comparé, 792-810. 